\title{
Complex Network-Driven View of Genomic Mechanisms Underlying Parkinson's Disease: Analyses in Dorsal Motor Vagal Nucleus, Locus Coeruleus, and Substantia Nigra
}

\author{
Beatriz Raposo Corradini, ${ }^{1}$ Priscila Iamashita, ${ }^{1}$ Edilaine Tampellini, ${ }^{2,3}$ \\ José Marcelo Farfel, ${ }^{3,4}$ Lea Tenenholz Grinberg, ${ }^{2,5,6}$ and Carlos Alberto Moreira-Filho ${ }^{1}$ \\ ${ }^{1}$ Department of Pediatrics, Faculdade de Medicina da USP (FMUSP), Avenida Dr. Enéas Carvalho Aguiar 647, 5 Andar, \\ 05403-900 São Paulo, SP, Brazil \\ ${ }^{2}$ Brazilian Aging Brain Study Group (BEHEEC), LIM 22, FMUSP, 01246-903 São Paulo, SP, Brazil \\ ${ }^{3}$ Hospital Israelita Albert Einstein, 05652-900 São Paulo, SP, Brazil \\ ${ }^{4}$ Division of Geriatrics, FMUSP, 01246-903 São Paulo, SP, Brazil \\ ${ }^{5}$ Department of Pathology, FMUSP, 01246-903 São Paulo, SP, Brazil \\ ${ }^{6}$ Department of Neurology and Pathology, University of California, San Francisco, CA 94143, USA
}

Correspondence should be addressed to Carlos Alberto Moreira-Filho; carlos.moreira@hc.fm.usp.br

Received 28 May 2014; Accepted 15 September 2014; Published 26 November 2014

Academic Editor: Meike Kasten

Copyright (C) 2014 Beatriz Raposo Corradini et al. This is an open access article distributed under the Creative Commons Attribution License, which permits unrestricted use, distribution, and reproduction in any medium, provided the original work is properly cited.

\begin{abstract}
Parkinson's disease (PD) — classically characterized by severe loss of dopaminergic neurons in the substantia nigra pars compactahas a caudal-rostral progression, beginning in the dorsal motor vagal nucleus and, in a less extent, in the olfactory system, progressing to the midbrain and eventually to the basal forebrain and the neocortex. About $90 \%$ of the cases are idiopathic. To study the molecular mechanisms involved in idiopathic PD we conducted a comparative study of transcriptional interaction networks in the dorsal motor vagal nucleus (VA), locus coeruleus (LC), and substantia nigra (SN) of idiopathic PD in Braak stages 4-5 (PD) and disease-free controls (CT) using postmortem samples. Gene coexpression networks (GCNs) for each brain region (patients and controls) were obtained to identify highly connected relevant genes (hubs) and densely interconnected gene sets (modules). GCN analyses showed differences in topology and module composition between CT and PD networks for each anatomic region. In CT networks, VA, LC, and SN hub modules are predominantly associated with neuroprotection and homeostasis in the ageing brain, whereas in the patient's group, for the three brain regions, hub modules are mostly related to stress response and neuron survival/degeneration mechanisms.
\end{abstract}

\section{Introduction}

Parkinson's disease (PD) is the second most common neurodegenerative disease worldwide [1]. Ageing is the main risk factor and about $90 \%$ of the cases are idiopathic [2]. PD features a substantial loss of neurons in the substantia nigra and locus coeruleus and systematic deposition of protein-rich aggregates in the brain as intracellular inclusions, forming the Lewy neurites and Lewy bodies [3]. $\alpha$-Synuclein is the most abundant protein found in Lewy bodies and usually aggregates in fibrillar structures [4]. The disease displays a caudal-rostral progression, starting in the dorsal motor vagal nucleus and, in a less extent, in the olfactory system, progressing to the limbic structures and up to the neocortex $[3,5,6]$. This progression pathway is the basis of the widely accepted Braak staging model of PD $[3,5,6]$. Recent studies have shown that misfolded $\alpha$-synuclein can be transferred between neurons in a prion-like manner and following the caudo-rostral progression pathway of Braak model [for revisions see $[4,7,8]]$. 
TABLE 1: Pathological data of patients and controls.

\begin{tabular}{lcccccc}
\hline $\begin{array}{l}\text { ID patients (PD) } \\
\text { and controls (CT) }\end{array}$ & Braak staging & Gender & Age (yrs) & \multicolumn{3}{c}{ Anatomic region* } \\
\hline PD1 & 4 & $\mathrm{~F}$ & 85 & $\mathrm{X}$ & & $\mathrm{X}$ \\
PD2 & 4 & $\mathrm{M}$ & 64 & $\mathrm{X}$ & $\mathrm{X}$ & $\mathrm{X}$ \\
PD3 & 4 & $\mathrm{M}$ & 66 & $\mathrm{X}$ & $\mathrm{X}$ & $\mathrm{X}$ \\
PD4 & 4 & $\mathrm{~F}$ & 80 & $\mathrm{X}$ & $\mathrm{X}$ & $\mathrm{X}$ \\
PD5 & 4 & $\mathrm{~F}$ & 84 & $\mathrm{X}$ & $\mathrm{X}$ & $\mathrm{X}$ \\
PD6 & 5 & $\mathrm{M}$ & 68 & $\mathrm{X}$ & $\mathrm{X}$ & $\mathrm{X}$ \\
PD7 & 5 & $\mathrm{M}$ & 82 & $\mathrm{X}$ & $\mathrm{X}$ & $\mathrm{X}$ \\
PD8 & 5 & $\mathrm{M}$ & 90 & $\mathrm{X}$ & $\mathrm{X}$ & $\mathrm{X}$ \\
CT1 & Control & $\mathrm{M}$ & 69 & & $\mathrm{X}$ & \\
CT2 & Control & $\mathrm{F}$ & 90 & & $\mathrm{X}$ & $\mathrm{X}$ \\
CT3 & Control & $\mathrm{M}$ & 64 & $\mathrm{X}$ & $\mathrm{X}$ & $\mathrm{X}$ \\
CT4 & Control & $\mathrm{M}$ & 70 & $\mathrm{X}$ & $\mathrm{X}$ & $\mathrm{X}$ \\
CT5 & Control & $\mathrm{M}$ & 85 & $\mathrm{X}$ & $\mathrm{X}$ & $\mathrm{X}$ \\
CT6 & Control & $\mathrm{M}$ & 58 & $\mathrm{X}$ & $\mathrm{X}$ & $\mathrm{X}$ \\
CT7 & Control & $\mathrm{F}$ & 70 & $\mathrm{X}$ & $\mathrm{X}$ & $\mathrm{X}$ \\
\hline
\end{tabular}

F: female; M: male; SN: substantia nigra; LC: locus coeruleus; VA: dorsal motor vagal nucleus; ${ }^{*}$ genomic study.

To better understand the molecular mechanisms underlying idiopathic PD, several studies compared global gene expression in postmortem samples (mostly in substantia nigra) from patients with PD and matched controls $[9,10]$. Global gene expression is a functional genomic approach based on data derived from DNA microarray technology and analyzed by bioinformatics tools [11]. Typically, these studies were focused on the identification of differentially expressed genes and of genes involved in particular molecular pathways $[9,10]$. Bioinformatics analysis was sometimes restricted to gene categorization [11]. A meta-analysis of 11 out 22 functional genomic studies conducted between 2004 and 2009 [10] failed to show a gene with reliable differential expression [9]. Nevertheless, six among nine studies reported deregulation in the metabolic pathways related to mitochondrial function/electron transportation, protein degradation, and synaptic transmission (only three reported alterations in dopamine signaling pathway) [9].

This scenario started to change with the introduction of statistical and computational tools for analyzing genegene interaction networks and the comparative analysis of gene expression and interactome [12]. Edwards et al. [13] used a typical systems biology approach to combine data from genome wide association studies (GWAS) and of gene expression in the six adjacent brain regions used for PD Braak staging. They found that calcium signaling, focal adhesion, and axonal guidance were the main consensus disease pathways in PD. Marei et al. [14] analyzing expression microarray data obtained from adult postmortem SN found that the genes enriched in SN cells included the following functional categories: synaptic transmission, central nervous system development, structural components of myelin sheath, internode region of axons, ion transport, and voltagegated ion channel complex.
The relevant genes to the pathogenesis of complex diseases, like idiopathic PD, are those with a high number of gene-gene links in transcriptional interaction networks, which do not necessary show what a high differential expression $[15,16]$. These highly connected genes, or hubs, are called "broker genes" in the sense that they connect many genes that would not be connected otherwise [15]. Therefore, gene coexpression network (GCN) studies may help to unravel molecular mechanisms in neurological diseases by offering genome-scale information. In fact, many recent investigations have shown that modular transcriptional repertoires, that is, communities of highly connected genes [17, 18], relate to fundamental features of brain activity and structure [19, 20]. Here, through DNA microarray gene expression data, we performed comparative analyses of gene coexpression networks (GCNs) in dorsal motor vagal nucleus (VA), locus coeruleus (LC), and substantia nigra (SN) of idiopathic Parkinson's disease patients at Braak stages 4-5 and matched controls using postmortem samples.

\section{Materials and Methods}

Postmortem samples of dorsal motor vagal nucleus (VA), locus coeruleus (LC), and substantia nigra (SN) from controls and PD subjects (Table 1) were obtained from the Brain Bank of the Brazilian Aging Brain Study Group, BEHEEC-FMUSP, under institutional (FMUSP) ethical committee approval $04 / 285$ [21]. The samples $\left(3-4 \mathrm{~mm}^{3}\right)$ were homogenized with Tissue Rupter (Qiagen, catalog number 9001272, Valencia, CA), and total RNA was extracted from the homogenates using the RNeasy Lipid Tissue Kit (Qiagen, catalog number 74804, Valencia, CA). RNA quality was assessed on the Agilent BioAnalyzer 2100 (Agilent, Santa Clara, CA). RNA 


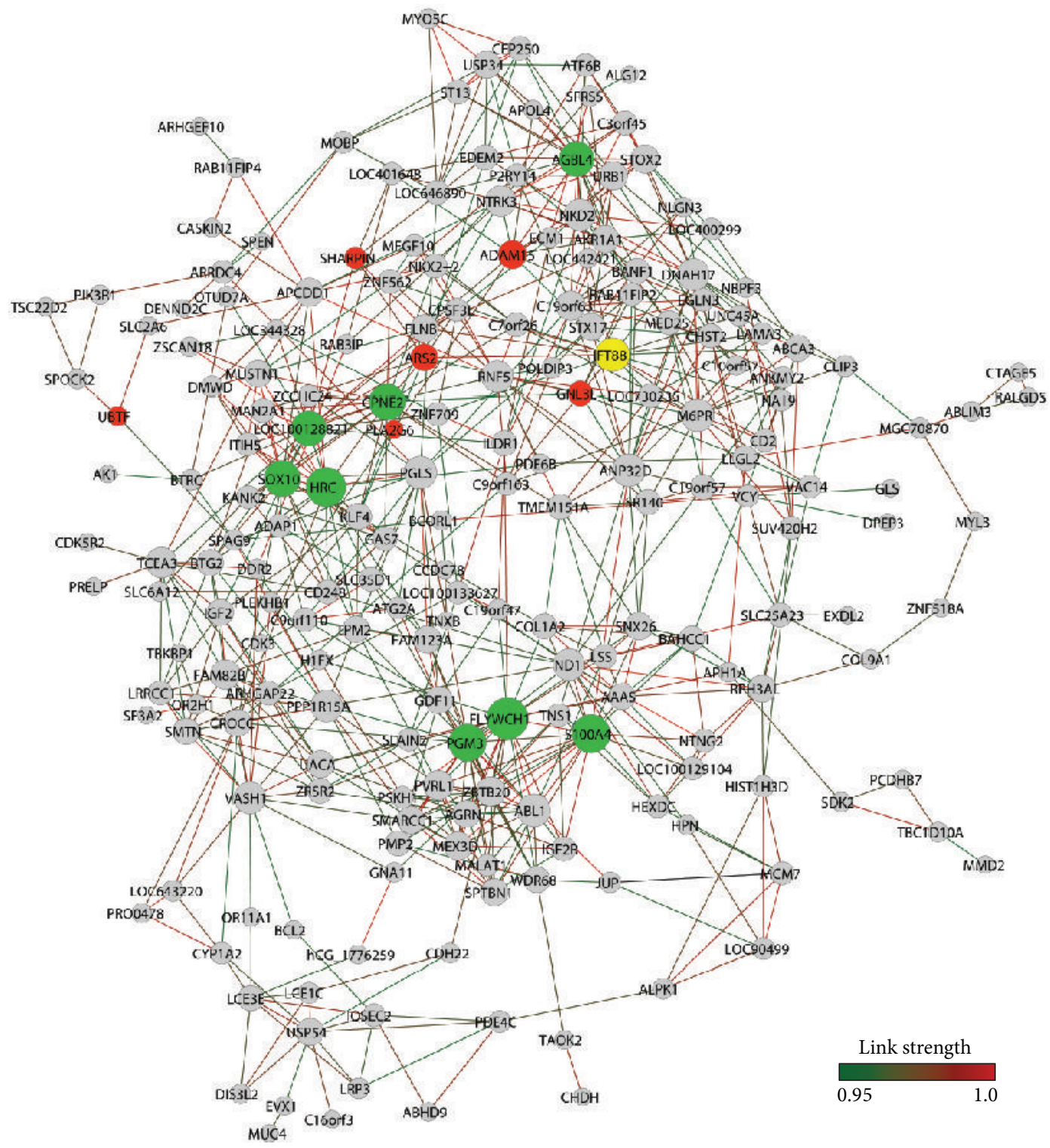

FIGURE 1: VA-CT gene expression network. Nodes in red indicate hubs of PD network, nodes in green indicate hubs of CT network, and node in yellow indicates a common hub of PD and CT networks.

integrity number (RIN) values were all within the acceptable range (6-7) for microarray assays using brain bank samples [22]. To determine gene expression profiles, $44 \mathrm{~K}$ DNA microarrays (Agilent Technologies, catalog number G4845A, Santa Clara, CA) were used. The procedures for hybridization followed the protocols provided by the manufacturer's instructions (One-Color Microarray-Based Gene Expression Analysis, Quick Amp Labeling). The images were captured by the reader Agilent Bundle according to the parameters recommended for BioArrays and extracted by Agilent Feature Extraction software version 9.5.3. Among the 45,015 spots present in each array only those with none or only one flag (i.e., low intensity, saturation, controls, etc.) were selected for analysis using the $\mathrm{R}$ software version 2.11.1
(R Development Core Team, 2010) and the Lowess test for normalization. We identified 17,142 valid transcripts for SN samples (8 PD and 5 CT cases), 20,705 valid transcripts for LC samples (7 DP and 7 CT cases), and 18,681 valid transcripts for VA samples (8 DP and 6 CT cases). By means of the TMEV software version 4.6.1 [17] we selected differentially expressed transcripts $(\mathrm{PD} \times \mathrm{CT})$. For LC samples, this comparison was performed using SAM (significance analysis of microarrays), whereas for SN and VA samples (nonparametric) Wilcoxon Mann-Whitney test $(P<0.005$ or $P<0.01$, resp.) was used. All microarray data were deposited in GEO public database (http://www.ncbi.nlm.nih.gov/geo) under accession number GE43490. Transcriptional interaction network for differentially expressed GO annotated genes was constructed based 


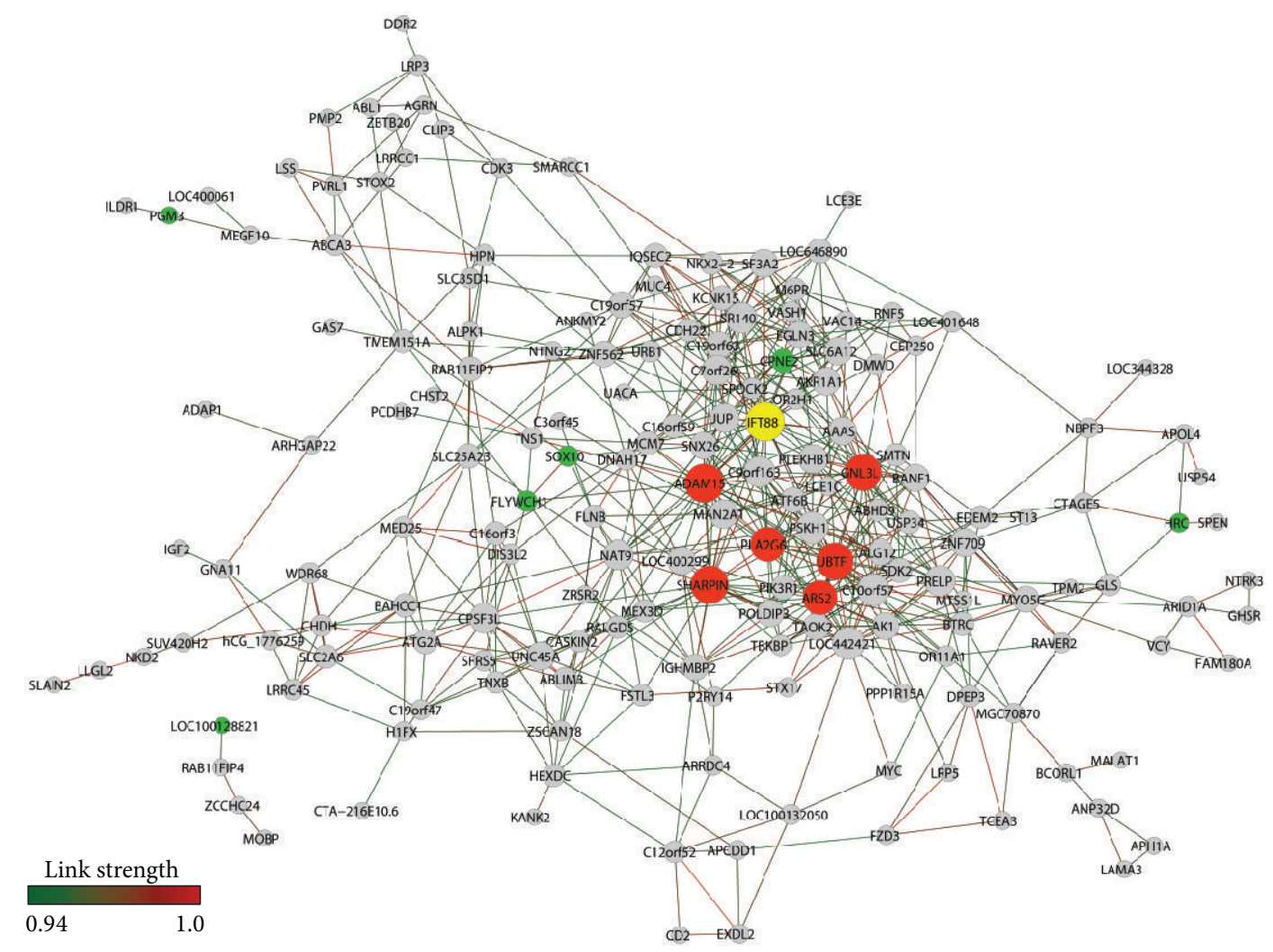

FIGURE 2: VA-PD gene expression network. Nodes in red indicate hubs of PD network, nodes in green indicate hubs of CT network, and node in yellow indicates a common hub of PD and CT networks.

on Pearson's correlation, using software R. Data analysis and visualization were achieved through Cytoscape software 2.8.0 (http://www.cytoscape.org/).

\section{Results and Discussion}

The comparative analysis of VA, LC, and SN transcriptomic profiles for patient (PD) versus control (CT) groups revealed 234, 183, and 326 differentially expressed GO annotated genes, respectively. All genes were upregulated in PD groups. Transcriptional interaction networks for each anatomic region (VA, LC, and $\mathrm{SN}$ ) for both groups were obtained and analyzed. In each of these six networks, the genes with the higher number of gene-gene links were considered hubs [21, 23 ] and the sets of highly interconnect genes were identified as modules [18-20].

\section{VA Networks}

A total of 178 genes and 646 gene-gene links (threshold 0.94) for VA-PD network and 206 genes and 670 gene-gene links (threshold 0.95) for VA-CT network were obtained, respectively (Figure 1 (VA-CT) and Figure 2 (VA-PD)). Network connectivity $k$ for nondirected networks was calculated by $k=2 L / N$, where $L$ stands for the number of edges and $N$ for the number of nodes [24]. $k$ values were 6.5 for VA-CT and 7.25 for VA-PD. Table 2 lists the selected VA hubs of CT and PD groups.

The VA-CT network displayed a modular structure with four clearly identifiable modules (Figure 1). Two of these modules showed a sole central hub; one is centered in AGBL4, a gene involved in controlling polyglutamate side chains which is a critical process for neuron survival [33], and the other in IFT88, which is a common hub of both VA-CT and VA-PD networks. IFT88 codes for a key component of intraflagellar transport were involved in dendrite patterning and synapse integration of adult-born neurons [34, 70, 71]. The other two modules encompass several highly linked hubs.

The first clusters were CPNE2, HRC, SOX10, and ZEB2 (former LOC100128821). CPNE2 and HRC are genes involved in brain $\mathrm{Ca}^{2+}$ metabolism and functions: $H R C$, or histidinerich calcium binding protein, regulates $\mathrm{Ca}^{2+}$ homeostasis [26], whereas CPNE2 acts as a $\mathrm{Ca}^{2+}$ sensor in postsynaptic events [32]. SOX10 and ZEB2 play a role in myelination processes: SOX10 codes for a transcription factor acting in regulating myelination in oligodendrocytes [31], and ZEB2, which codes for a Smad-interacting protein, acts in myelination of the central nervous system [72] and regulates the fate switch between cortical and striatal interneurons [73].

The second module harbored the genes S100A4, PGM3, and FLYWCH1. S100A4 codes for a $\mathrm{Ca}^{2+}$-binding protein were involved in neuroprotection, rescuing neurons via the 
TABLE 2: Main hubs in VA-CT and VA-PD networks*.

\begin{tabular}{|c|c|c|c|}
\hline \multirow{2}{*}{ Gene } & \multicolumn{2}{|c|}{ Gene-gene links } & \multirow{2}{*}{ Gene product and/or biological function } \\
\hline & $\mathrm{CT}$ & $\mathrm{PD}$ & \\
\hline FLYWCH1 & 23 & 6 & FLYWCH-type zinc finger 1. DNA binding. Involved in transcriptional regulation [25] \\
\hline HRC & 21 & 4 & Histidine rich calcium binding protein. Regulator of $\mathrm{Ca}^{2+}$ homeostasis [26] \\
\hline S100A4 & 20 & 0 & $\begin{array}{l}\text { S100A4 } \mathrm{Ca}^{2+} \text {-binding protein involved in neuroprotection. It rescues neurons via the Janus } \\
\text { kinase/STAT pathway and, partially, the interleukin-10 receptor }[27,28]\end{array}$ \\
\hline PGM3 & 19 & 2 & $\begin{array}{l}\text { Phosphoglucomutase 3. PGM3 is involved in glycogenolysis and glycogenesis; these } \\
\text { processes provide metabolic energy for cellular calcium homeostasis [29] and causes } \\
\text { hypomyelination when mutated [30] }\end{array}$ \\
\hline SOX10 & 18 & 6 & $\begin{array}{l}\text { Transcription factor. Involved in regulatory network for myelination in oligodendrocytes } \\
\text { [31] }\end{array}$ \\
\hline CPNE2 & 18 & 0 & Calcium-dependent membrane binding protein. $\mathrm{Ca}^{2+}$ sensor in postsynaptic events [32] \\
\hline LOC100128821 & 17 & 1 & Hypothetical protein LOC100128821 \\
\hline AGBL4 & 17 & 0 & $\begin{array}{l}\text { ATP/GTP binding protein-like } 4 \text {. CCP6 (aliase). CCP6 catalyzes the shortening of the } \\
\text { glutamate side chains, a critical process for neuron survival [33] }\end{array}$ \\
\hline IFT88 & 16 & 26 & $\begin{array}{l}\text { Key component of intraflagellar transport and involved in neuron migration and dendrite } \\
\text { arborization [34] }\end{array}$ \\
\hline ADAM15 & 11 & 26 & Metalloprotease-disintegrin expressed in brain and involved in neuroprotection [35] \\
\hline SHARPIN & 5 & 25 & $\begin{array}{l}\text { Ubiquitin-binding and ubiquitin-like-domain-containing protein. It modulates activation of } \\
\text { NF- } \kappa \text { B signaling pathway and controls cell survival and apoptosis [36-38] }\end{array}$ \\
\hline GNL3L & 8 & 24 & $\begin{array}{l}\text { Guanine nucleotide binding protein-like } 3 \text { nucleolar-like, paralogue of nucleostemin (NS). } \\
\text { GNL3L, as NS, stabilizes MDM2 protein promoting neuron survival }[39,40]\end{array}$ \\
\hline UBTF & 3 & 24 & $\begin{array}{l}\text { Upstream binding transcription factor, RNA polymerase I (aliase UBF), is a transcriptional } \\
\text { activator regulating rRNA transcription. The activation of the nucleolar transcription is a } \\
\text { response to proteotoxic stress in neurons [41] }\end{array}$ \\
\hline ARS2 & 10 & 21 & Ars2 maintains neural stem cell identity via direct transcriptional activation of Sox2 [42] \\
\hline PLA2G6 & 2 & 21 & $\begin{array}{l}\text { Phospholipase A2, group VI (cytosolic, calcium-independent), PARK14 (aliase). PARK14 } \\
\text { gene encodes iPLA2-VIA, a calcium independent phosphatase, catalyzing the hydrolysis of } \\
\text { glycerophospholipids. Mutations in this gene can cause autosome recessive early-onset form } \\
\text { of PD }[43,44]\end{array}$ \\
\hline
\end{tabular}

* Bold numbers indicate highly linked hubs in CT and/or PD networks.

Janus kinase/STAT pathway and, partially, via interleukin10 receptor [27], and promoting neuritogenesis and survival [28]. PGM3 codes for a phosphoglucomutase involved in glycogenesis and glycogenolysis; these processes provide energy for cellular calcium homeostasis [29] and cause hypomyelination when mutated [30]. FLYWCH1 codes a FLYWCH-type zinc finger 1 chromatin modulator protein. Cellular proteins that harbor the FLYWCH domain are predominantly involved in transcriptional regulation [25]. Altogether, the VA-CT modules encompass genes associated with neuron survival and protection, $\mathrm{Ca}^{2+}$ homeostasis, myelination, and neuron differentiation.

The VA-PD network (Figure 2) had, comparatively with VA-CT, a totally distinct topology and modular distribution. The highly connected hubs are all included in a single module. The majority of these genes take part in molecular and cellular processes related to stress responses. ADAM15, which codes for a disintegrin metalloprotease, has been implicated in both the process of neuronal hypoxic injury [35] and the protection (via GRP78 binding) of neurons from hypoxia-induced apoptosis [74]. SHARPIN codes for a ubiquitin-binding and ubiquitin-like-domain-containing protein, which is an important component of the linear ubiquitin chain assembly complex (LUBAC) that modulates activation of NF- $\kappa$ B signaling pathway, thus controlling cell survival and apoptosis [36-38]. GNL3 codes for a nucleolar protein which stabilizes MDM2 (a nuclear-localized E3 ubiquitin ligase) in the nucleoplasm [39] and promotes neuronal survival [40]. UBTF codes for a protein playing critical roles in ribosomal RNA transcription and chromatin remodeling, which takes part in the compensatory response to proteotoxic stress in neurons [41]. ARS2 participates in maintaining neuronal stem cell identity via direct transcriptional activation of Sox2 [42]. Finally, PLA2G6, aliase PARK14, codes for a phospholipase A2, group 6 which hydrolases membrane phospholipids and may contribute, via lipid peroxidation, to CNS injury and disorders, such as Parkinson's disease [43]. Not surprisingly, mutations in this gene cause an autosome recessive earlyonset form of Parkinson's disease with widespread Lewy bodies [44].

\section{LC Networks}

A total of 121 genes and 659 gene-gene links (threshold 0.92 ) and 164 genes and 645 gene-gene links (threshold 0.90 ) were obtained for LC-PD network and LC-CT network, 
TABLE 3: Main hubs in LC-CT and LC-PD networks* .

\begin{tabular}{|c|c|c|c|}
\hline \multirow{2}{*}{ Gene } & \multicolumn{2}{|c|}{ Gene-gene links } & \multirow{2}{*}{ Gene product and/or biological function } \\
\hline & CT & $\mathrm{PD}$ & \\
\hline GPRC5B & 30 & 6 & $\begin{array}{l}\text { Orphan G protein-coupled receptor (putative glutamate receptor candidate) required for } \\
\text { neuronal differentiation [45] }\end{array}$ \\
\hline GRM3 & 23 & 4 & $\begin{array}{l}\text { Group II metabotropic glutamate receptor modulating glutamate neurotransmission and } \\
\text { synaptic plasticity. It plays a role in neuroprotection and white matter integrity [46-48] }\end{array}$ \\
\hline UGT8 & 23 & 1 & $\begin{array}{l}\text { UDP glycosyltransferase } 8 \text {. Highly expressed in brain oligodendrocytes. Involved in } \\
\text { myelination and maintenance of white matter tracts within the central nervous system } \\
{[49,50]}\end{array}$ \\
\hline NUDT13 & 21 & 23 & Mitochondrial enzyme (Nudix hydrolase) involved in response to oxidative stress [51] \\
\hline SEPP1 & 21 & 1 & $\begin{array}{l}\text { Selenoprotein P, plasma, 1. Maintains selenium homeostasis in the brain. Involved in } \\
\text { antioxidant protection of astrocytes and neurons [52] }\end{array}$ \\
\hline RGS5 & 20 & 25 & Regulator of G protein signaling 5. It is a marker of brain pericytes [53] \\
\hline PCOLCE2 & 20 & 5 & $\begin{array}{l}\text { Procollagen C-endopeptidase enhancer } 2 \text { [54]. It regulates apoAI posttranslational } \\
\text { processing [55] }\end{array}$ \\
\hline PPP4R1 & 4 & 40 & Protein phosphatase 4 catalytic unit [56] \\
\hline FAM5B & 12 & 35 & $\begin{array}{l}\text { BRINP2 (aliase). BMP/RA-inducible neural specific protein. BRINP1, BRINP2, and BRINP3 } \\
\text { are predominantly and widely expressed in both the central nervous system (CNS) and the } \\
\text { peripheral nervous system (PNS) and involved in neuron development [57] }\end{array}$ \\
\hline MED30 & 17 & 32 & $\begin{array}{l}\text { Mediator of RNA polymerase II transcription subunit } 30 \text {. Required for oxidative } \\
\text { phosphorylation and mitochondrial integrity [58] }\end{array}$ \\
\hline TOB2 & 11 & 29 & $\begin{array}{l}\text { TOB2 regulates mRNA deadenylation, potentiates NGF-induced differentiation, and } \\
\text { protects neurons from apoptosis }[59,60]\end{array}$ \\
\hline ZNRF3 & 11 & 29 & $\begin{array}{l}\text { ZNRF3 promotes Wnt receptor turnover [61]. Wnt signaling is linked to synaptic } \\
\text { maintenance in the aging brain [62] and regulation of inflammatory pathways along PD } \\
\text { progression [63] }\end{array}$ \\
\hline PARP4 & 3 & 29 & Poly-ADP-ribose polymerase controlling synaptic plasticity via major vault protein [64] \\
\hline ATXN1 & 12 & 28 & $\begin{array}{l}\text { Polyglutamine-containing protein. Polyglutamine (polyQ) disease gene putatively involved } \\
\text { in autosomal dominant Parkinson's disease [65] }\end{array}$ \\
\hline SFRS18 & 3 & 28 & $\begin{array}{l}\text { Serine-arginine rich protein (aliase SF2/AFS) regulates protein sumoylation [66]. Protein } \\
\text { sumoylation inhibits alfa-synuclein aggregation and toxicity [67] }\end{array}$ \\
\hline GAS7 & 10 & 26 & $\begin{array}{l}\text { Growth arrest-specific gene } 7 \text { (Gas7) is involved in neurite outgrowth and motor neuron } \\
\text { function }[68,69]\end{array}$ \\
\hline
\end{tabular}

${ }^{*}$ Bold numbers indicate highly linked hubs in CT and or PD networks.

respectively. $k$ values were 7.86 and 10.89 for LC-CT (Figure 3) and LC-PD (Figure 4). Table 3 lists the selected LC hubs for $\mathrm{CT}$ and PD groups.

In the LC-CT network the majority of the highly connected hubs were clustered in one large module encompassing several genes related to neuroprotection and maintenance of myelinated fibers in the aging brain (Figure 3 ). In this large module, two genes play a role in response to oxidative stress and antioxidant protection: NUDT13, a common hub of both LC-CT and LC-PD networks, facilitates the elimination of oxidized forms of $\mathrm{NAD}(\mathrm{P}) \mathrm{H}$ and $\mathrm{CoA}$ cofactors from peroxisomes, mitochondria, and the cytoplasm [51], whereas SEPP1 codes for a brain antioxidant selenoprotein secreted by astrocytes and taken up by neurons via the apolipoprotein E receptor 2 [52]. GRM3, the metabotropic glutamate receptor 3 gene, and UGT8, UDP-glucuronosyltransferase 8 , are closely interconnected hubs of the LC-CT network (Figure 3) and exert important protective roles for the aging brain. GMR3 is expressed by glia and neurons in many brain regions [46] and acts not only in glutamate transmission but also in the establishment and maintenance of myelinated fibers [47] and protection against mitochondrial neurotoxins [48]. UGT8 is involved in oligodendrocyte differentiation [49] and myelination processes [50]. GPR5B codes for a G protein-coupled receptor, which is a member of the group $\mathrm{C}$ metabotropic glutamate receptor family. This protein is required for neuronal fate determination in the brain [45] and GPR5B downregulation affects microglial activation [75]. Directly linked to GPR5B (Figure 3) appears PCOLCE2, a gene coding for a procollagen C-proteinase enhancer [54] and involved in the regulation of proapolipoprotein (apo) AI (apoAI) posttranslational processing [55]: apoAI binds $\beta$ amyloid peptide, a major protein in the brain associated with Alzheimer's and Parkinson's diseases, thus preventing Abetainduced neurotoxicity [76].

Lastly, a relatively small module was organized around RGS5 (Figure 3), a regulator of $\mathrm{G}$ protein signaling and a well-known marker for brain pericytes [53, 77]. Pericytes contribute to the control of endothelial tight-junction cells and blood-brain barrier (BBB) function. There is a correlation 


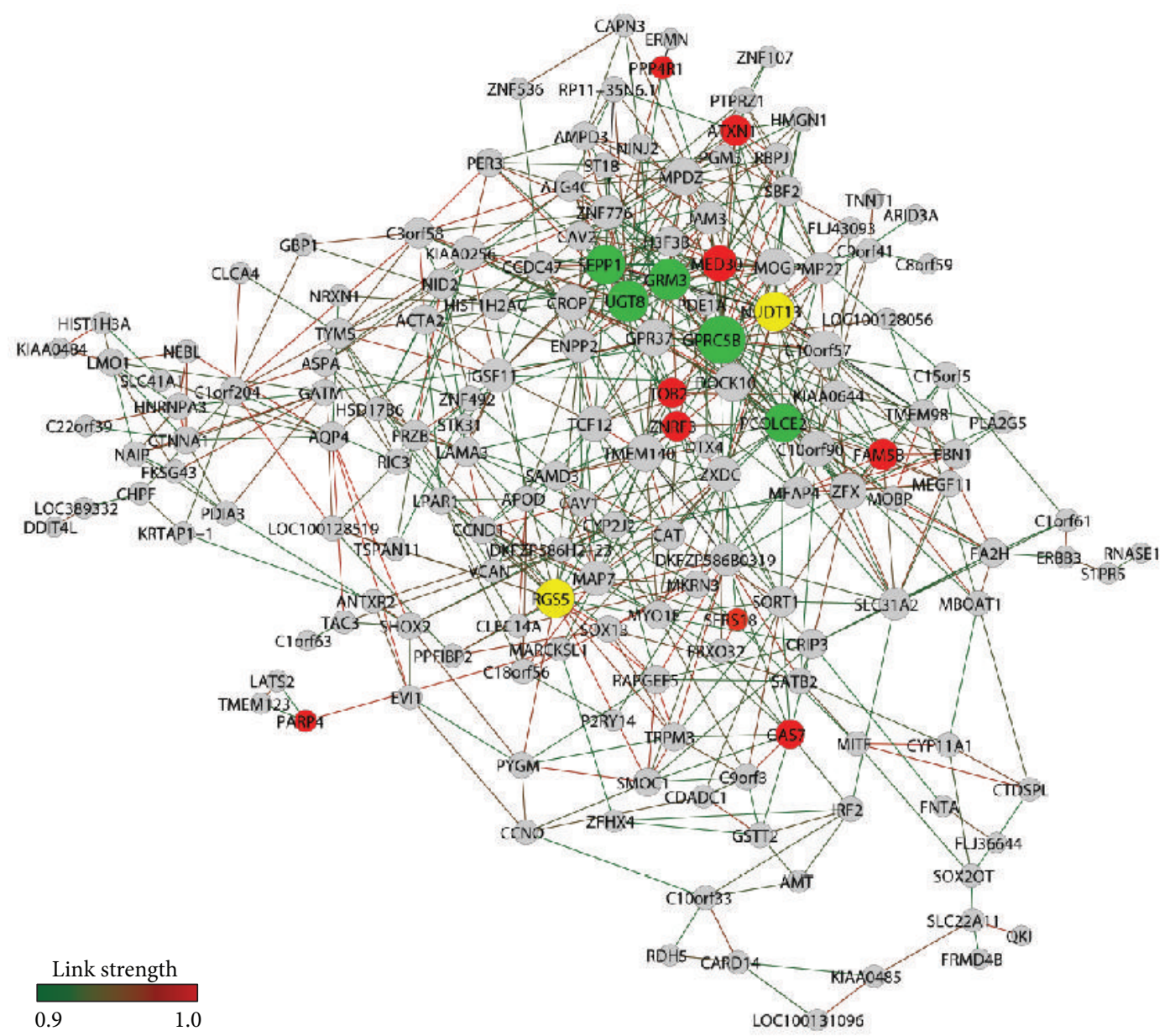

Figure 3: LC-CT gene expression network. Nodes in red indicate hubs of PD network, nodes in green indicate hubs of CT network, and nodes in yellow indicate common hubs of PD and CT networks.

between BBB dysfunction and the progression of Parkinson's disease [78]. Interestingly, RGS5 is a common hub of LC-CT and LC-PD networks.

In the LC-PD network all highly linked hubs are clustered in a single central module (Figure 4). Inside this module, eight out eleven genes are associated with neuroprotection and brain homeostasis. Two of these genes, NUDT13 and RGS5, were common hubs of LC-CT network and their roles have been already described. Two other genes, PPP4R1 which codes for a protein phosphatase 4 catalytic unity [56] and ATXN1 which codes for a polyglutamine-containing protein (polyQ) and may cause neurodegenerative diseases depending on the length of polyQ expansions [65], modulate transcriptional repression through binding to histone deacetylase $3[79,80]$. Transcriptional repression is an important epigenetic mechanism controlling the expression of essential genes for neuron survival and its imbalance may cause PD [81].

The remaining four genes in this set also exert relevant functions in neuroprotection and brain homeostasis, some of them possibly linked to repairing cellular injuries in $\mathrm{PD}$, as discussed below.

The gene MED30, which codes for the mediator of polymerase II transcription subunit 30, participates in oxidative phosphorylation and mitochondrial integrity [58]. TOB2 regulates mRNA deacetylation, potentiates NGF-induced differentiation, and protects neurons from apoptosis [59, 60]. SFRS18 (aliases SF2/AFS) codes for a serine-arginine rich protein which regulates protein sumoylation [66], a process required for inhibiting $\alpha$-synuclein aggregation and toxicity [67]. Finally, ZNFR3, a gene coding for a cell surface transmembrane E3 ubiquitin ligase zinc and ring finger 3, promotes Wnt receptor turnover [61]. This gene is critical because Wnt signaling is linked to (i) synaptic maintenance in the adult aging brain [62], (ii) regulation of inflammatory pathways along PD progression [63], and (iii) differentiation of LC noradrenergic neuronal precursors [104]. Recent findings indicate that dysregulation of the crosstalk between Wnt/ $\beta$-catenin signaling and antioxidant/anti-inflammatory pathways leads to the decline of subventricular zone (SVZ) plasticity with age and the limited nigrostriatal dopaminergic 


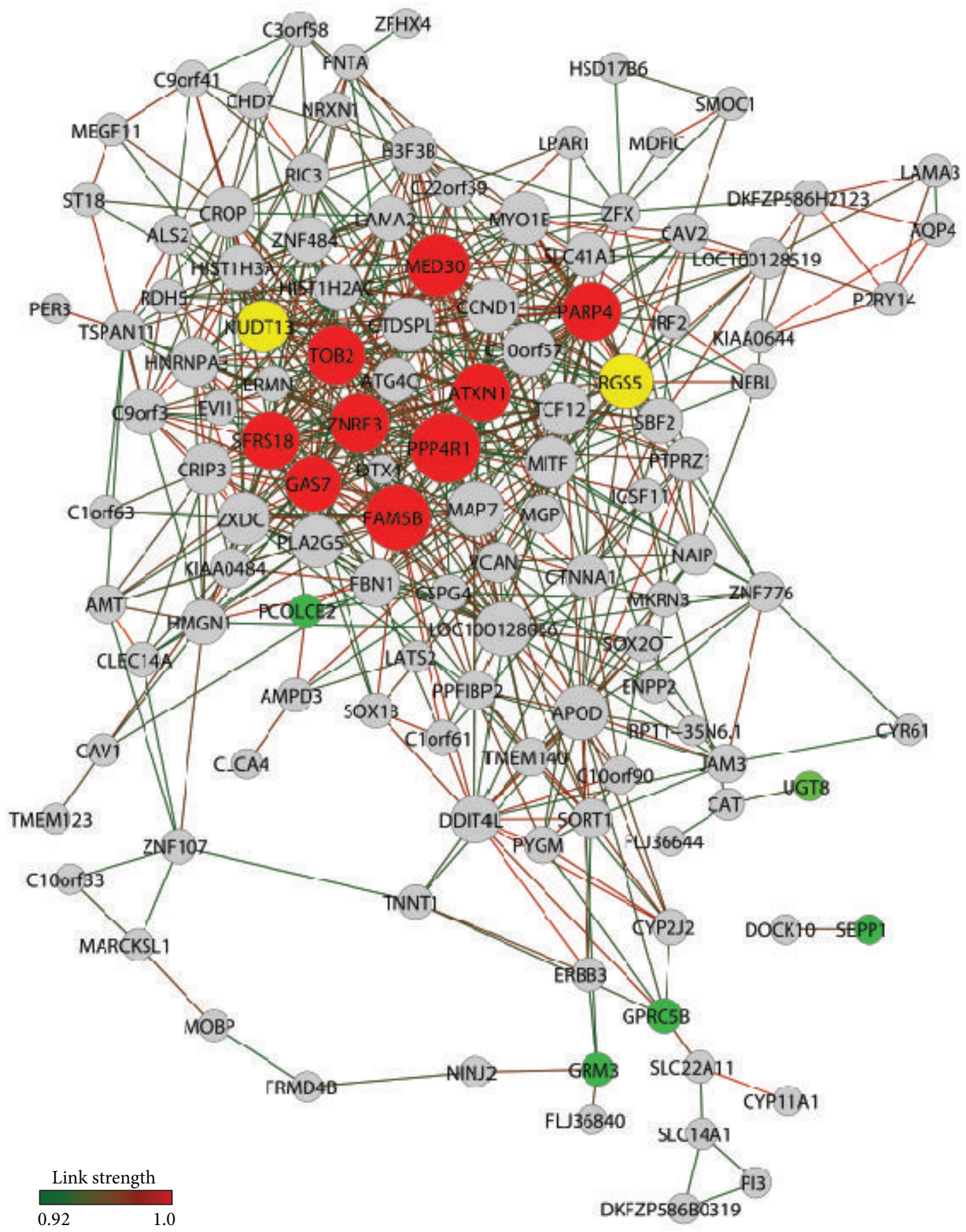

FIGURE 4: LC-PD gene expression network. Nodes in red indicate hubs of PD network, nodes in green indicate hubs of CT network, and nodes in yellow indicate common hub of PD and CT networks.

self-repair in PD [63]. Therefore, further investigation on the role of ZNFR3 in PD would be necessary.

Furthermore, inside the main hub cluster (Figure 4) three genes can be related to repair functions in PD: the growth arrest-specific gene 7, or GAS7, which promotes neurite outgrowth and motor neuron function [68, 69], FAM5B, alias BRIMP2, which codes for a BMP/RA-induced neural protein widely expressed in the central nervous system and related to neuron growth [57], and PARP4, which codes for a polyADP-ribose polymerase involved in the control of synaptic plasticity via major vault protein [64].

Therefore, in LC-PD there is an important activity of genes that could exert repair or compensatory mechanisms. In PD, the compensatory mechanisms at cellular and molecular levels are centered in protection against neurotoxicity $[105,106]$ and neurogenesis and reinnervation of affected 
TABLE 4: Main hubs in SN-CT and SN-PD networks*.

\begin{tabular}{|c|c|c|c|}
\hline \multirow{2}{*}{ Gene } & \multicolumn{2}{|c|}{ Gene-gene links } & \multirow{2}{*}{ Gene product and/or biological function } \\
\hline & $\mathrm{CT}$ & $\mathrm{PD}$ & \\
\hline SIRT1 & 19 & 10 & $\begin{array}{l}\text { Nicotinamide adenine dinucleotide- (NAD+-) dependent deacetylase (sirtuin } 1 \text { ) promotes } \\
\text { axonal elongation, neurite outgrowth, and dendritic branching. Sirtuin } 1 \text { plays a relevant } \\
\text { protective role in PD }[82,83]\end{array}$ \\
\hline ZFP112 & 19 & 8 & Zinc finger protein 112 homolog \\
\hline SHC4 & 18 & 5 & $\begin{array}{l}\text { SHC (Src homology } 2 \text { domain containing) family, member } 4 \text { (aliase ShcD), interacts with } \\
\text { tropomyosin receptor kinase B, trkB [84], the high affinity receptor for BDNF expressed in } \\
\text { striatal neurons. BNDF can reverse neuronal injury associated with PD [85] }\end{array}$ \\
\hline TMEM123 & 18 & 0 & $\begin{array}{l}\text { Transmembrane protein } 123 \text {, a cell surface receptor mediating oncotic cell death [86]. } \\
\text { Oncosis may be triggered by oxidative stress [87] and is important for neuronal homeostasis } \\
\text { [88] }\end{array}$ \\
\hline BCKDHB & 17 & 17 & $\begin{array}{l}\text { Branched chain keto acid dehydrogenase E1, beta polypeptide, a multienzyme complex } \\
\text { associated with the inner membrane of mitochondria, functioning in the catabolism of } \\
\text { branched chain amino acids. BCKDHB is essential for glutathione homeostasis }[89,90]\end{array}$ \\
\hline CBFB & 17 & 4 & $\begin{array}{l}\text { Core-binding factor, beta subunit, is a transcription factor that plays critical roles in neuron } \\
\text { development }[91,92]\end{array}$ \\
\hline CLDND1 & 9 & 26 & $\begin{array}{l}\text { Claudin 1. Claudin-family proteins are involved in tight-junction formation at the } \\
\text { blood-brain barrier (Luissint et al., 2012 [78]) and CLDN1 is expressed in the substantia } \\
\text { nigra compacta [93] }\end{array}$ \\
\hline GLDN & 3 & 22 & $\begin{array}{l}\text { Gliomedin (Gldn) secreted by Schwann cell microvilli binds NgCAM-related CAM } \\
\text { (NrCAM) and neurofascin-186 (NF186); it mediates heterotypic cell-cell adhesion }[94,95]\end{array}$ \\
\hline MBTD1 & 11 & 21 & $\begin{array}{l}\text { Member of the Polycomb group (PcG) protein family. It binds the Rb-E2F complex and } \\
\text { contributes to cell cycle progress and apoptosis }[96,97]\end{array}$ \\
\hline ARID4B & 6 & 19 & $\begin{array}{l}\text { Chromatin remodeling gene coding for a protein associated with mSIN3A histone } \\
\text { deacetylase complex [98]. It is involved in neuronal apoptosis [99] }\end{array}$ \\
\hline HNRNPA3 & 6 & 18 & Shuttling RNA transporter found in neuronal RNA granules and P-bodies [100] \\
\hline SORT1 & 15 & 16 & $\begin{array}{l}\text { Sortilin } 1 \text { is a member of the family of vacuolar protein sorting } 10 \text { protein domain receptors. } \\
\text { It is a coreceptor in cell death and neurodegeneration processes mediated by } \\
\text { proneurotrophins }[101,102] \text {; it contributes to neuronal apoptosis or neurodegeneration } \\
\text { during pathogenesis and progression of Parkinson's disease [103]. }\end{array}$ \\
\hline
\end{tabular}

* Bold numbers indicate highly linked hubs in CT and or PD networks.

areas [107]. These mechanisms are more active in the initial and intermediate stages of $\mathrm{PD}$, declining in the final stages $[108,109]$.

\section{SN Networks}

A total of 209 genes and 586 gene-gene links (threshold 0.94) and 199 genes and 682 gene-gene links (threshold 0.97 ) were obtained for SN-PD network and SN-CT network, respectively. $k$ values were 6.85 and 5.60 for SN-CT and SNPD. Figure 5 depicts SN-CT and Figure 6 depicts SN-PD. Table 4 lists the selected SN hubs of CT and PD groups.

In the control group network (SN-CT), the highly linked hubs were clustered in two modules (Figure 5). One module has $C B F B$ as a center, a gene coding for the beta subunit of a core-binding transcription factor belonging to the PEBP2/CBF transcription factor family which controls the transcriptional regulation of neurotrophin receptors, some ion channels, and neuropeptides, playing important roles in neuron development $[91,92]$. The other module encompassed the remaining six SN-CT hubs.
Two hubs, BCKDHB and SIRT1, were closely linked (Figure 5) and play significant roles in neuroprotection and brain homeostasis. $B C K D H B$, which is a common hub of SN-CT and SN-PD networks, codes for a branched-chain keto acid dehydrogenase E1 beta polypeptide, a multienzyme complex associated with the inner membrane of mitochondria that acts in the catabolism of branched-chain amino acids and is essential for glutathione homeostasis [89, 90]. SIRT1 codes for a NAD-dependent deacetylase (sirtuin 1) and play important neuroprotective roles in the aging brain and PD [82]. SIRT1 deacetylates heat shock factor 1 (HSF1), increasing the transcription of molecular chaperones such as heat shock protein 70. SIRT1 interacts with peroxisome proliferator-activated receptor-gamma coactivator- $1 \alpha$ (PGC$1 \alpha$ ) to reduce oxidative stress and increase the viability of dopaminergic neurons [83]. Moreover, SIRT1 may also regulate autophagy and mitophagy, which may diminish $\alpha$ synuclein toxicity in PD [110]. Interestingly, these two genes interact directly with SORT1 (sortilin1), a common hub of SNCT and SN-PD networks. Sortilin is a member of the family of vacuolar protein sorting 10 protein domain receptors. It is a coreceptor in cell death and neurodegeneration processes 


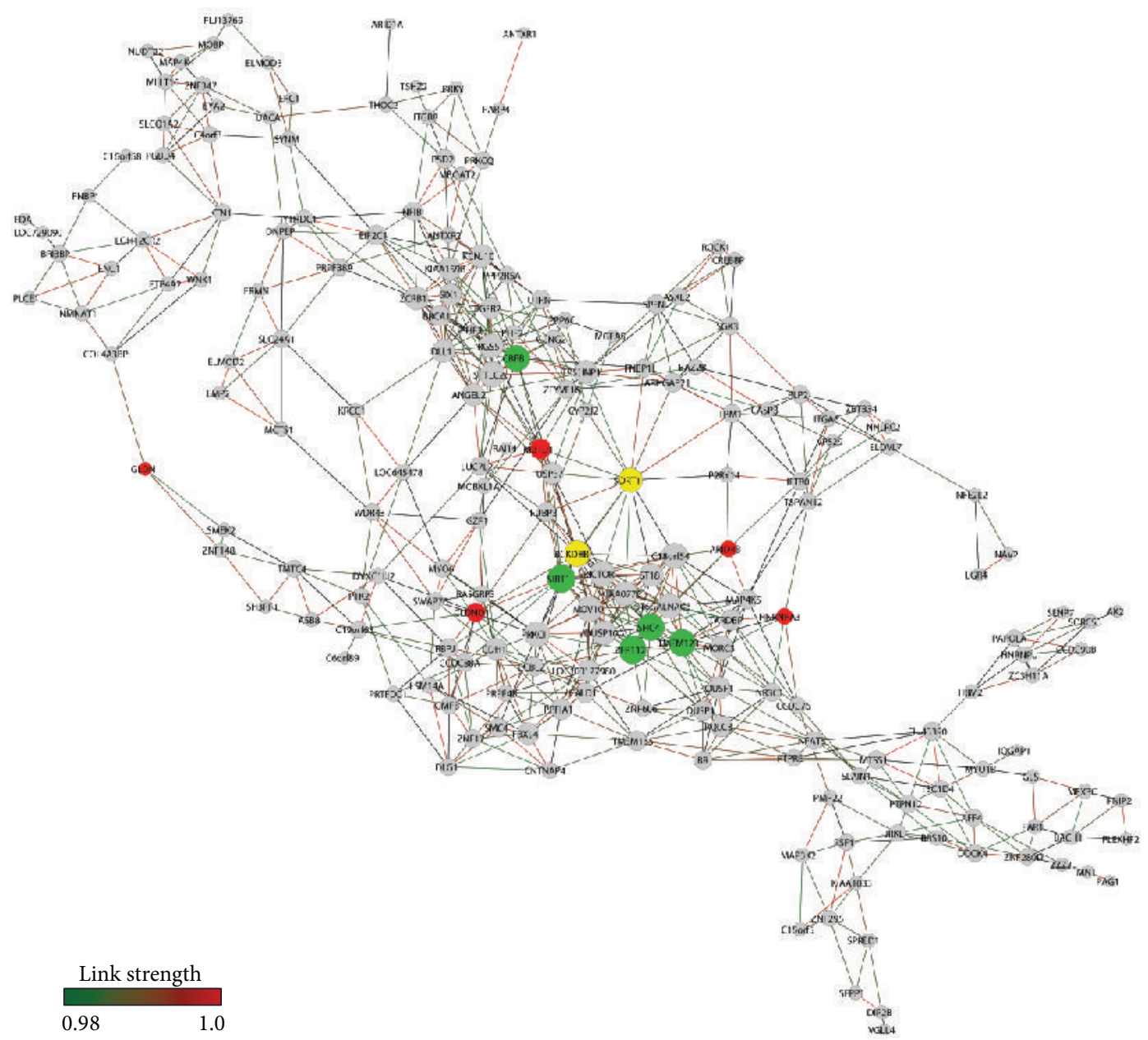

FIGURE 5: SN-CT gene expression network. Nodes in red indicate hubs of PD network, nodes in green indicate hubs of CT network, and nodes in yellow indicate common hubs of PD and CT networks.

mediated by proneurotrophins (proNT) [101, 102] and it might contribute to neuronal apoptosis or neurodegeneration during pathogenesis and disease progression of Parkinson's disease [103]. It is worth to note that proNT-mediated cell death is also relevant in normal development and during senescence of the nervous system: SIRT1 expression is altered in the aging brain and aged neurons are more sensitive to proNT-induced killing than young ones [111]. Consequently, sortilin may contribute to brain's functional integrity during normal physiological conditions.

Three other hubs are ZFP112, a gene coding for an unknown zinc-finger protein, and SHC4 and TMEM123, both having relevant roles in neuronal homeostasis. SHC4 codes for a Src homology and collagen (Shc) protein that interacts with tropomyosin receptor kinase B, trkB [84], the high affinity receptor for BDNF expressed in striatal neurons. BNDF can reverse neuronal injury associated with PD [85]. TMEM123 codes for transmembrane protein 123, a cell surface receptor mediating oncolytic cell death [86]. Oncosis may be triggered by oxidative stress [87], and it is important for neuronal homeostasis [88]. Altogether, the SN-CT network presented a situation compatible with SN functioning in the aging brain.

Conversely, the SN-DP network showed a significant change in the modular structure with all the highly connected hubs clustered in a single module (Figure 6). Two of these hubs, BCKDHB and SORT1 (previously discussed), are common to both SN-CT and SN-PD networks. The most connected hub in SN-PD network (Table 4) was CLDN1, a gene which codes for claudin 1, a protein expressed in substantia nigra pars compacta [93] and involved in tightjunction formation at the BBB [78]. In fact, BBB dysfunction occurs in many neurodegenerative diseases, such as PD [78]. The second most connect hub is GLDN, a gene coding for gliomedin, a molecule well known for mediating heterotypic cell-cell adhesion and interacting with neurofascin186 (NF186) and neuronal cell adhesion molecule (NrCAM) in the molecular assembly of the nodes of Ranvier in the peripheral nervous system $[94,95]$. Since functional genomic studies show that dopaminergic neurons in adult human SN 


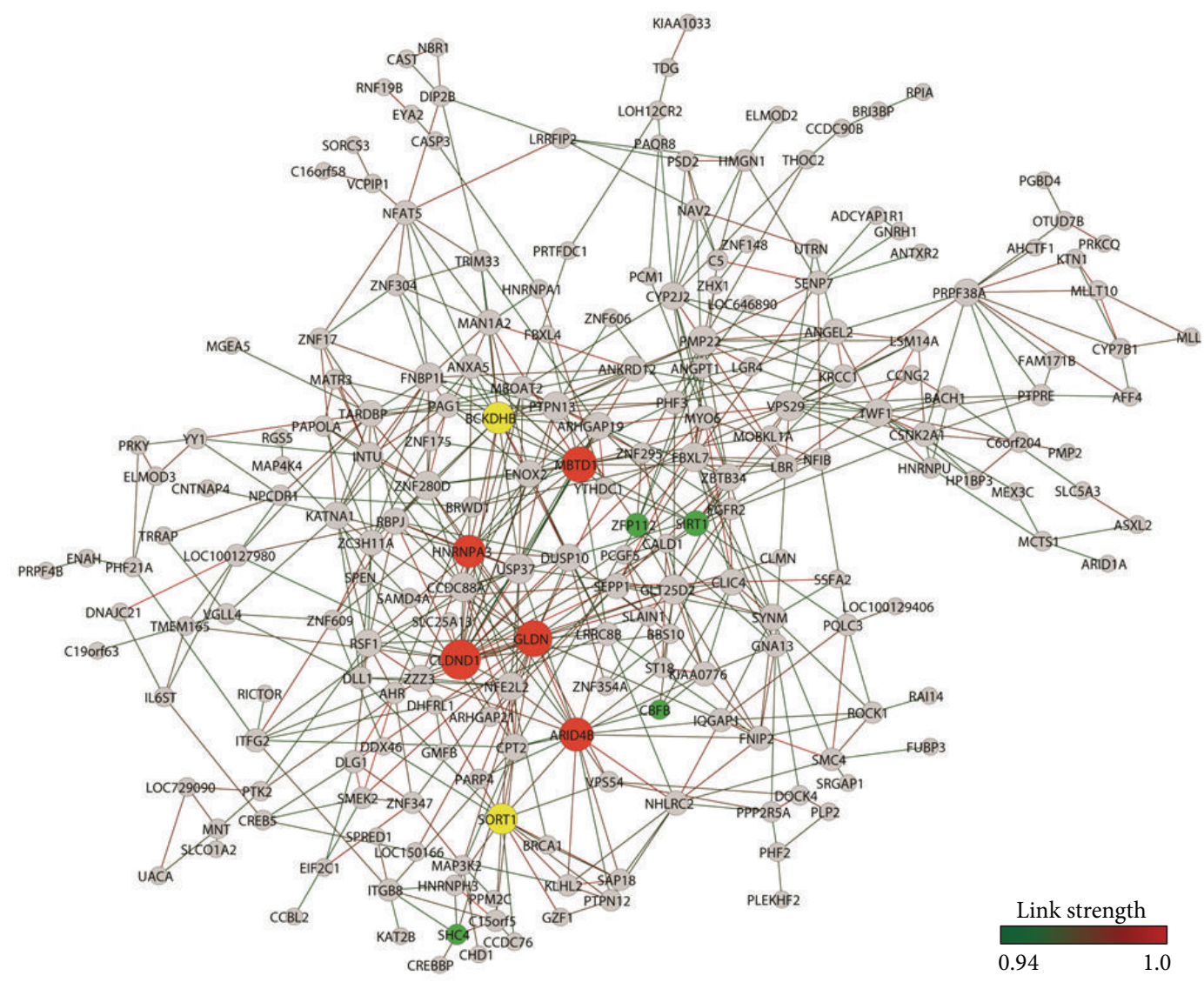

FiguRE 6: SN-PD gene expression network. Nodes in red indicate hubs of PD network, nodes in green indicate hubs of CT network, and nodes in yellow indicate common hubs of PD and CT networks.

support, or modulate, myelin sheath formation and voltagegated ion channel activity [14], it is reasonable to assume that GLDN expressed in SN cells could have a role in these processes. Furthermore, diffusion tensor imaging studies showed significant regional (substantia nigra) and global white matter deterioration in PD [112].

The last three SN-PD hubs, ARID4B, MBTD1, and HNRNPA3, have been shown to participate in biological processes associated with neurodegeneration. ARID4B is a chromatin remodeling gene coding for a protein associated with the mSIN3A histone deacetylase (HDAC) complex [98], which participates in neuronal apoptosis and transcriptional signaling in neurodegenerative diseases [99]. MBTD1 is a member of the Polycomb gene family [113], and its protein product binds the Rb- (retinoblastoma-) E2F complex [96], thus contributing to cell cycle progress and apoptosis [97]. In $\mathrm{PD}$, the $\mathrm{Rb}$-E2F pathway activates mitosis-like signals in dopaminergic neurons of SN pars compacta mediating the death of these cells [114]. HNRNPA3 codes for a shuttling RNA transporter found in the neuronal RNA granules and P-bodies [100]. These structures are associated with altered ribostasis, dendrite sprouting, and neurodegeneration $[115,116]$. Here is important to note that SIRT1, a SNCT hub, exerts its neuroprotective action by inhibiting the
ARID4B/mSINA3/HDAC transcriptional repression activity [117]. This SIRT1 activity gets apparently attenuated in the SNPD network.

The SN-PD transcriptional network profile, with a predominance of hubs linked to neurodegenerative processes (although retaining one hub involved in glutathione homeostasis and another in response to oxidative stress, both common to SN-CT), would be expected to be found in the SN of patients in Braak stages 4-5 [3, 8, 118-120].

Solid evidences now exist that PD has a caudal-rostral progression, being initiated in the dorsal motor vagal nucleus and/or olfactory bulb, progressing to the midbrain and eventually to the basal forebrain and the neocortex $[3,5,6]$ through a prion-like mechanism of neuron-neuron transfer of altered $\alpha$-synuclein molecules [4, 8, 121]. The SN, affected by Lewy body pathology in the Braak stages 3-4 of PD [3, $5,6]$, showed in this study (Braak stages 4-5), diminished activation of genic circuits linked to neuroprotection when compared to the genomic profiles in VA and LC. Diminished activation is in agreement with the well-established fact that clinical diagnosis of PD can be made from Braak stage 3 onwards, although patients may present prodromal signs in early stages $[119,121]$. It is worth to note that even in Braak stages 4-5 the genes linked to neuroprotection display high 
connectivity in VA and LC networks, what indicates that these genes are actively coordinating their particular cellular processes [17].

\section{Conclusions}

This report shows that transcriptional interaction network analysis, an effective methodology for dealing with a large set of genomic data $[17,19,20]$, allowed the comparative study of transcriptome signatures in VA, LC, and $\mathrm{SN}$ in PD. These analyses identified the highly connected hubs and hub modules that possibly play relevant roles in the brain aging and/or PD progression. Accordingly, the comparative analysis between hub profiles in different anatomic regions for PD patients and controls revealed interesting scenario.

In VA-CT, the main hubs are associated with $\mathrm{Ca}^{2+}$ homeostasis, myelination, and neuroprotection in the aging brain, whereas, in VA-PD, the relevant hubs are mostly related to compensatory responses to proteotoxic stress. Interestingly, one of these hubs is PARK14 (alias PLA2G6), a gene causing autosome recessive early-onset $\mathrm{PD}$ when mutated [44]. The LC-CT hubs are mainly associated with protection against oxidative and proteotoxic stress, myelination, and BBB maintenance. The majority of LC-PD hubs are also linked to neuroprotection and brain homeostasis, although in the context of repairing/compensating various $\mathrm{PD}$-associated cellular injuries (SFRS18, ZFNR3, and FAM5B, for instance). Finally, the SN-CT main hubs include genes that are critical for neuroprotection and homeostasis in the aging brain, such as SIRT1 and BCKDHB. Conversely, the SN-PD network displays a very different landscape: six out seven hubs are associated with neurodegenerative processes. These results are compatible with the caudo-rostral model of PD progression and point out to the usefulness of GCNs approach for (i) investigating the molecular mechanisms underlying idiopathic PD and (ii) identifying novel therapeutic targets based on the concept of interventions aimed to restore altered regulatory network structures $[19,20,122]$.

\section{Conflict of Interests}

The authors declare that there is no conflict of interests regarding the publication of this paper.

\section{Acknowledgments}

This work was funded by Fundação de Amparo à Pesquisa do Estado de São Paulo (FAPESP) research Grants 2009/534431 and 2011/50761-2 (FAPESP-MCT/CNPq/PRONEX) and by Conselho Nacional de Desenvolvimento Científico e Tecnológico (CNPq) Grant 305635/2009-3 to CAM-F. LTG is funded by NIH R01AG040311. The authors would like to thank Patricia L. Ramos for help in microarray work and Silvia Yumi Bando for revising gene expression data analyses.

\section{References}

[1] A. H. V. Schapira, "Neurobiology and treatment of Parkinson's disease," Trends in Pharmacological Sciences, vol. 30, no. 1, pp. 41-47, 2009.

[2] O. Corti, S. Lesage, and A. Brice, "What genetics tells us about the causes and mechanisms of Parkinson's disease," Physiological Reviews, vol. 91, no. 4, pp. 1161-1218, 2011.

[3] A. E. Kingsbury, R. Bandopadhyay, L. Silveira-Moriyama et al., "Brain stem pathology in Parkinson's disease: an evaluation of the Braak staging model," Movement Disorders, vol. 25, no. 15, pp. 2508-2515, 2010.

[4] C. Hansen and J. Y. Li, "Beyond $\alpha$-synuclein transfer: pathology propagation in Parkinson's disease," Trends in Molecular Medicine, vol. 18, no. 5, pp. 248-255, 2012.

[5] H. Braak, K. Del Tredici, U. Rüb, R. A. I. de Vos, E. N. H. J. Steur, and E. Braak, "Staging of brain pathology related to sporadic Parkinson's disease," Neurobiology of Aging, vol. 24, no. 2, pp. 197-211, 2003.

[6] H. Braak, U. Rüb, W. P. Gai, and K. Del Tredici, "Idiopathic Parkinson's disease: possible routes by which vulnerable neuronal types may be subject to neuroinvasion by an unknown pathogen," Journal of Neural Transmission, vol. 110, no. 5, pp. 517-536, 2003.

[7] C. J. R. Dunning, J. F. Reyes, J. A. Steiner, and P. Brundin, "Can Parkinson's disease pathology be propagated from one neuron to another?" Progress in Neurobiology, vol. 97, no. 2, pp. 205-219, 2012.

[8] O. Marques and T. F. Outeiro, "Alpha-synuclein: from secretion to dysfunction and death," Cell Death and Disease, vol. 3, no. 7, article e350, 2012.

[9] J. G. Greene, "Current status and future directions of gene expression profiling in Parkinson's disease," Neurobiology of Disease, vol. 45, no. 1, pp. 76-82, 2012.

[10] P. A. Lewis and M. R. Cookson, "Gene expression in the Parkinson's disease brain," Brain Research Bulletin, vol. 88, no. 4, pp. 302-312, 2012.

[11] S. W. Scholz, T. Mhyre, H. Ressom, S. Shah, and H. J. Federoff, "Genomics and bioinformatics of Parkinson's disease," Cold Spring Harbor Perspectives in Medicine, vol. 2, no. 7, Article ID a009449, 2012.

[12] T. Ideker and N. J. Krogan, "Differential network biology," Molecular Systems Biology, vol. 8, article 565, 2012.

[13] Y. J. Edwards, G. W. Beecham, W. K. Scott et al., "Identifying consensus disease pathways in Parkinson's disease using an integrative systems biology approach," PLoS ONE, vol. 6, no. 2, Article ID e16917, 2011.

[14] H. E. S. Marei, A. Althani, N. Afifi et al., "Gene expression profiling of embryonic human neural stem cells and dopaminergic neurons from adult human substantia nigra," PLoS ONE, vol. 6, no. 12, Article ID e28420, 2011.

[15] J. J. Cai, E. Borenstein, and D. A. Petrov, "Broker genes in human disease," Genome Biology and Evolution, vol. 2, pp. 815-825, 2010.

[16] S. Chavali, F. Barrenas, K. Kanduri, and M. Benson, "Network properties of human disease genes with pleiotropic effects," BMC Systems Biology, vol. 4, article 78, 2010.

[17] A.-L. Barabasi, N. Gulbahce, and J. Loscalzo, "Network medicine: a network-based approach to human disease," Nature Reviews Genetics, vol. 12, no. 1, pp. 56-68, 2011. 
[18] D. Chaussabel and N. Baldwin, "Democratizing systems immunology with modular transcriptional repertoire analyses," Nature Reviews Immunology, vol. 14, no. 4, pp. 271-280, 2014.

[19] S. Y. Bando, F. N. Silva, L. D. F. Costa et al., "Complex network analysis of CA3 transcriptome reveals pathogenic and compensatory pathways in refractory temporal lobe epilepsy," PLoS ONE, vol. 8, no. 11, Article ID e79913, 2013.

[20] C. Gaiteri, Y. Ding, B. French, G. C. Tseng, and E. Sibille, "Beyond modules and hubs: the potential of gene coexpression networks for investigating molecular mechanisms of complex brain disorders," Genes, Brain and Behavior, vol. 13, no. 1, pp. 13-24, 2014.

[21] L. T. Grinberg, R. E. Lucena Ferretti, J. M. Farfel et al., "Brain bank of the Brazilian aging brain study group-a milestone reached and more than 1,600 collected brains," Cell and Tissue Banking, vol. 8, no. 2, pp. 151-162, 2007.

[22] L. Opitz, G. Salinas-Riester, M. Grade et al., "Impact of RNA degradation on gene expression profiling," BMC Medical Genomics, vol. 3, article 36, 2010.

[23] M. T. Weirauch, "Gene expression network for the analysis of cDNA microarray data," in Applied Statistics for Network Biology: Methods in Systems Biology, M. Dehmer, F. EmmertStreib, A. Graber, and A. Salvador, Eds., vol. 1, pp. 215-250, Wiley-Blackwell, Weinheim, Germany, 2011.

[24] M. E. J. Newman, Networks: An Introduction, Oxford University Press, New York, NY, USA, 2010.

[25] C. P. Marquez and E. J. Pritham, "Phantom, a new subclass of Mutator DNA transposons found in insect viruses and widely distributed in animals," Genetics, vol. 185, no. 4, pp. 1507-1517, 2010.

[26] C. D. Arvanitis, M. Bazan-Peregrino, B. Rifai, L. W. Seymour, and C. C. Coussios, "Cavitation-enhanced extravasation for drug delivery," Ultrasound in Medicine and Biology, vol. 37, no. 11, pp. 1838-1852, 2011.

[27] O. Dmytriyeva, S. Pankratova, S. Owczarek et al., "The metastasis-promoting S100A4 protein confers neuroprotection in brain injury," Nature Communications, vol. 3, article 1197, 2012.

[28] M. Moldovan, V. Pinchenko, O. Dmytriyeva et al., "Peptide mimetic of the S100A4 protein modulates peripheral nerve regeneration and attenuates the progression of neuropathy in myelin protein P0 null mice," Molecular Medicine, vol. 19, no. 1, pp. 43-53, 2013.

[29] M. S. Müller, R. Fox, A. Schousboe, H. S. Waagepetersen, and L. K. Bak, "Astrocyte glycogenolysis is triggered by storeoperated calcium entry and provides metabolic energy for cellular calcium homeostasis," GLIA, vol. 62, no. 4, pp. 526-534, 2014.

[30] Y. Zhang, X. Yu, M. Ichikawa et al., "Autosomal recessive phosphoglucomutase 3 (PGM3) mutations link glycosylation defects to atopy, immune deficiency, autoimmunity, and neurocognitive impairment," Journal of Allergy and Clinical Immunology, vol. 133, no. 5, pp. 1400-1409, 2014.

[31] J. Hornig, F. Fröb, M. R. Vogl, I. Hermans-Borgmeyer, E. R. Tamm, and M. Wegner, "The transcription factors Sox10 and Myrf define an essential regulatory network module in differentiating oligodendrocytes," PLoS Genetics, vol. 9, no. 10, Article ID e1003907, 2013.

[32] T. Nakayama, T. Yaoi, and G. Kuwajima, "Localization and subcellular distribution of N-copine in mouse brain," Journal of Neurochemistry, vol. 72, no. 1, pp. 373-379, 1999.
[33] K. Rogowski, J. van Dijk, M. M. Magiera et al., "A family of protein-deglutamylating enzymes associated with neurodegeneration," Cell, vol. 143, no. 4, pp. 564-578, 2010.

[34] A. Louvi and E. A. Grove, "Cilia in the CNS: the quiet organelle claims center stage," Neuron, vol. 69, no. 6, pp. 1046-1060, 2011.

[35] E. Rybnikova, T. Gluschenko, A. Galeeva et al., "Differential expression of ADAM15 and ADAM17 metalloproteases in the rat brain after severe hypobaric hypoxia and hypoxic preconditioning," Neuroscience Research, vol. 72, no. 4, pp. 364-373, 2012.

[36] F. Ikeda, Y. L. Deribe, S. S. Skånland et al., "SHARPIN forms a linear ubiquitin ligase complex regulating NF- $\kappa \mathrm{B}$ activity and apoptosis," Nature, vol. 471, no. 7340, pp. 637-641, 2011.

[37] Z. Wang, C. S. Potter, J. P. Sundberg, and H. Hogenesch, "SHARPIN is a key regulator of immune and inflammatory responses," Journal of Cellular and Molecular Medicine, vol. 16, no. 10, pp. 2271-2279, 2012.

[38] F. Tokunaga, "Linear ubiquitination-mediated NF- $\kappa$ B regulation and its related disorders," Journal of Biochemistry, vol. 154, no. 4, pp. 313-323, 2013.

[39] L. Meng, J. K. Hsu, and R. Y. L. Tsai, "GNL3L depletion destabilizes MDM2 and induces p53-dependent G2/M arrest," Oncogene, vol. 30, no. 14, pp. 1716-1726, 2011.

[40] T. Engel, A. Sanz-Rodgriguez, E. M. Jimenez-Mateos et al., "CHOP regulates the p53-MDM2 axis and is required for neuronal survival after seizures," Brain, vol. 136, no. 2, pp. 577592, 2013.

[41] A. Palanca, I. Casafont, M. T. Berciano, and M. Lafarga, "Reactive nucleolar and Cajal body responses to proteasome inhibition in sensory ganglion neurons," Biochimica et Biophysica Acta: Molecular Basis of Disease, vol. 1842, no. 6, pp. 848-859, 2014.

[42] C. Andreu-Agullo, T. Maurin, C. B. Thompson, and E. C. Lai, "Ars2 maintains neural stem-cell identity through direct transcriptional activation of Sox2," Nature, vol. 481, no. 7380, pp. 195-198, 2012.

[43] R. M. Adibhatla and J. F. Hatcher, "Phospholipase $A_{2}$, reactive oxygen species, and lipid peroxidation in CNS pathologies," BMB Reports, vol. 41, no. 8, pp. 560-567, 2008.

[44] V. Bonifati, "Genetics of Parkinson's disease-state of the art, 2013," Parkinsonism and Related Disorders, vol. 20, supplement 1, pp. S23-S28, 2014.

[45] N. Kurabayashi, M. D. Nguyen, and K. Sanada, "The G proteincoupled receptor GPRC5B contributes to neurogenesis in the developing mouse neocortex," Development (Cambridge), vol. 140, no. 21, pp. 4335-4346, 2013.

[46] P. J. Harrison, L. Lyon, L. J. Sartorius, P. W. J. Burnet, and T. A. Lane, "The group II metabotropic glutamate receptor 3 (mGluR3, mGlu3, GRM3): expression, function and involvement in schizophrenia," Journal of Psychopharmacology, vol. 22, no. 3, pp. 308-322, 2008.

[47] J. Mounce, L. Luo, A. Caprihan, J. Liu, N. I. Perrone-Bizzozero, and V. D. Calhoun, "Association of GRM3 polymorphism with white matter integrity in schizophrenia," Schizophrenia Research, vol. 155, no. 1-3, pp. 8-14, 2014.

[48] D. Jantas, A. Greda, S. Golda et al., "Neuroprotective effects of metabotropic glutamate receptor group II and III activators against $\mathrm{MPP}(+)$-induced cell death in human neuroblastoma SH-SY5Y cells: the impact of cell differentiation state," Neuropharmacology, vol. 83, pp. 36-53, 2014. 
[49] J. C. Dugas, Y. C. Tai, T. P. Speed, J. Ngai, and B. A. Barres, "Functional genomic analysis of oligodendrocyte differentiation," Journal of Neuroscience, vol. 26, no. 43, pp. 10967-10983, 2006.

[50] A. M. Manzardo, S. Gunewardena, and M. G. Butler, "Overexpression of the miRNA cluster at chromosome $14 \mathrm{q} 32$ in the alcoholic brain correlates with suppression of predicted target mRNA required for oligodendrocyte proliferation," Gene, vol. 526, no. 2, pp. 356-363, 2013.

[51] A. G. McLennan, "The Nudix hydrolase superfamily," Cellular and Molecular Life Sciences, vol. 63, no. 2, pp. 123-143, 2006.

[52] H. Steinbrenner and H. Sies, "Selenium homeostasis and antioxidant selenoproteins in brain: implications for disorders in the central nervous system," Archives of Biochemistry and Biophysics, vol. 536, no. 2, pp. 152-157, 2013.

[53] M. H. Nisancioglu, W. M. Mahoney Jr., D. D. Kimmel, S. M. Schwartz, C. Betsholtz, and G. Genové, "Generation and characterization of rgs5 mutant mice," Molecular and Cellular Biology, vol. 28, no. 7, pp. 2324-2331, 2008.

[54] B. Stieglitz, L. F. Haire, I. Dikic, and K. Rittinger, "Structural analysis of SHARPIN, a subunit of a large multi-protein E3 ubiquitin ligase, reveals a novel dimerization function for the pleckstrin homology superfold," The Journal of Biological Chemistry, vol. 287, no. 25, pp. 20823-20829, 2012.

[55] J. Zhu, J. Gardner, C. R. Pullinger, J. P. Kane, J. F. Thompson, and O. L. Francone, "Regulation of apoAI processing by procollagen C-proteinase enhancer-2 and bone morphogenetic protein-1," Journal of Lipid Research, vol. 50, no. 7, pp. 1330-1339, 2009.

[56] K. Toyo-oka, D. Mori, Y. Yano et al., "Protein phosphatase 4 catalytic subunit regulates Cdk1 activity and microtubule organization via NDEL1 dephosphorylation," The Journal of Cell Biology, vol. 180, no. 6, pp. 1133-1147, 2008.

[57] M. Terashima, M. Kobayashi, M. Motomiya et al., "Analysis of the expression and function of BRINP family genes during neuronal differentiation in mouse embryonic stem cell-derived neural stem cells," Journal of Neuroscience Research, vol. 88, no. 7, pp. 1387-1393, 2010.

[58] P. Krebs, W. Fan, Y.-H. Chen et al., "Lethal mitochondrial cardiomyopathy in a hypomorphic Med30 mouse mutant is ameliorated by ketogenic diet," Proceedings of the National Academy of Sciences of the United States of America, vol. 108, no. 49, pp. 19678-19682, 2011.

[59] G. Corrente, D. Guardavaccaro, and F. Tirone, "PC3 potentiates NGF-induced differentiation and protects neurons from apoptosis," NeuroReport, vol. 13, no. 4, pp. 417-422, 2002.

[60] N. Ezzeddine, C.-Y. A. Chen, and A.-B. Shyu, "Evidence providing new insights into TOB-promoted deadenylation and supporting a link between TOB's deadenylation-enhancing and antiproliferative activities," Molecular and Cellular Biology, vol. 32, no. 6, pp. 1089-1098, 2012.

[61] H.-X. Hao, Y. Xie, Y. Zhang et al., "ZNRF3 promotes Wnt receptor turnover in an R-spondin-sensitive manner," Nature, vol. 484, no. 7397, pp. 195-200, 2012.

[62] S. A. Purro, S. Galli, and P. C. Salinas, "Dysfunction of Wnt signaling and synaptic disassembly in neurodegenerative diseases," Journal of Molecular Cell Biology, vol. 6, no. 1, pp. 7580, 2014.

[63] F. L'Episcopo, C. Tirolo, S. Caniglia et al., "Targeting Wnt signaling at the neuroimmune interface for dopaminergic neuroprotection/repair in Parkinson's disease," Journal of Molecular Cell Biology, vol. 6, no. 1, pp. 13-26, 2014.
[64] J. A. Papalas, N. N. Balmer, C. Wallace, and O. P. Sangüeza, "Ossifying dermatofibroma with osteoclast-like giant cells: report of a case and literature review," American Journal of Dermatopathology, vol. 31, no. 4, pp. 379-383, 2009.

[65] C. Yamashita, H. Tomiyama, M. Funayama et al., "The evaluation of polyglutamine repeats in autosomal dominant Parkinson's disease," Neurobiology of Aging, vol. 35, no. 7, pp. 1779.e171779.e21, 2014.

[66] F. Pelisch, J. Gerez, J. Druker et al., "The serine/arginine-rich protein SF2/ASF regulates protein sumoylation," Proceedings of the National Academy of Sciences of the United States of America, vol. 107, no. 37, pp. 16119-16124, 2010.

[67] P. Krumova, E. Meulmeester, M. Garrido et al., "Sumoylation inhibits $\alpha$-synuclein aggregation and toxicity," The Journal of Cell Biology, vol. 194, no. 1, pp. 49-60, 2011.

[68] B. T. Huang, P. Y. Chang, C. H. Su, C. C. Chao, and S. LinChao, "Gas7-deficient mouse reveals roles in motor function and muscle fiber composition during aging," PLoS ONE, vol. 7, no. 5, Article ID e37702, 2012.

[69] A. Gotoh, M. Hidaka, K. Hirose, and T. Uchida, "Gas7b (growth arrest specific protein $7 \mathrm{~b}$ ) regulates neuronal cell morphology by enhancing microtubule and actin filament assembly," Journal of Biological Chemistry, vol. 288, no. 48, pp. 34699-34706, 2013.

[70] N. Kumamoto, Y. Gu, J. Wang et al., "A role for primary cilia in glutamatergic synaptic integration of adult-born neurons," Nature Neuroscience, vol. 15, no. 3, pp. 399-405, 2012.

[71] S. M. Guadiana, S. Semple-Rowland, D. Daroszewski et al., "Arborization of dendrites by developing neocortical neurons is dependent on primary cilia and type 3 adenylyl cyclase," The Journal of Neuroscience, vol. 33, no. 6, pp. 2626-2638, 2013.

[72] Q. Weng, Y. Chen, H. Wang et al., "Dual-mode modulation of Smad signaling by Smad -interacting protein Sip1 is required for myelination in the central nervous system," Neuron, vol. 73, no. 4, pp. 713-728, 2012.

[73] G. L. McKinsey, S. Lindtner, B. Trzcinski et al., "Dlx1\&2dependent expression of Zfhxlb (Sip1, Zeb2) regulates the fate switch between cortical and striatal interneurons," Neuron, vol. 77, no. 1, pp. 83-98, 2013.

[74] N. Goldenberg-Cohen, A. Raiter, V. Gaydar et al., "Peptidebinding GRP78 protects neurons from hypoxia-induced apoptosis," Apoptosis, vol. 17, no. 3, pp. 278-288, 2012.

[75] H. J. Chung, J. D. Kim, K. H. Kim, and N. Y. Jeong, "G proteincoupled receptor, family C, group 5 (GPRC5B) downregulation in spinal cord neurons is involved in neuropathic pain," Korean Journal of Anesthesiology, vol. 66, no. 3, pp. 230-236, 2014.

[76] A. C. Paula-Lima, M. A. Tricerri, J. Brito-Moreira et al., "Human apolipoprotein A-I binds amyloid- $\beta$ and prevents $A \beta$-induced neurotoxicity," The International Journal of Biochemistry and Cell Biology, vol. 41, no. 6, pp. 1361-1370, 2009.

[77] G. D. Stanwood, J. P. Parlaman, and P. Levitt, "Genetic or pharmacological inactivation of the dopamine D1 receptor differentially alters the expression of regulator of G-protein signalling (Rgs) transcripts," The European Journal of Neuroscience, vol. 24, no. 3, pp. 806-818, 2006.

[78] A.-C. Luissint, C. Artus, F. Glacial, K. Ganeshamoorthy, and P.-O. Couraud, "Tight junctions at the blood brain barrier: Physiological architecture and disease-associated dysregulation," Fluids and Barriers of the CNS, vol. 9, no. 1, article 23, 2012.

[79] A. Venkatraman, Y. S. Hu, A. Didonna et al., "The histone deacetylase HDAC3 is essential for Purkinje cell function, potentially complicating the use of HDAC inhibitors in SCA1," Human Molecular Genetics, vol. 23, no. 14, pp. 3733-3745, 2014. 
[80] X. Zhang, Y. Ozawa, H. Lee et al., "Histone deacetylase 3 (HDAC3) activity is regulated by interaction with protein serine/threonine phosphatase 4," Genes and Development, vol. 19, no. 7, pp. 827-839, 2005.

[81] I. F. Harrison and D. T. Dexter, "Epigenetic targeting of histone deacetylase: therapeutic potential in Parkinson's disease?” Pharmacology and Therapeutics, vol. 140, no. 1, pp. 34-52, 2013.

[82] A. Z. Herskovits and L. Guarente, "SIRT1 in neurodevelopment and brain senescence," Neuron, vol. 81, no. 3, pp. 471-483, 2014.

[83] G. Mudò, J. Mäkelä, V. Di Liberto et al., “Transgenic expression and activation of PGC- $1 \alpha$ protect dopaminergic neurons in the MPTP mouse model of Parkinsons disease," Cellular and Molecular Life Sciences, vol. 69, no. 7, pp. 1153-1165, 2012.

[84] Y. You, W. Li, Y. Gong et al., "ShcD interacts with TrkB via its PTB and SH2 domains and regulates BDNF-induced MAPK activation," BMB Reports, vol. 43, no. 7, pp. 485-490, 2010.

[85] M. E. Fenner, C. L. Achim, and B. M. Fenner, "Expression of fulllength and truncated trkB in human striatum and substantia nigra neurons: Implications for Parkinson's disease," Journal of Molecular Histology, vol. 45, no. 3, pp. 349-361, 2014.

[86] F. Ma, C. Zhang, K. V. S. Prasad, G. J. Freeman, and S. F. Schlossman, "Molecular cloning of porimin, a novel cell surface receptor mediating oncotic cell death," Proceedings of the National Academy of Sciences of the United States of America, vol. 98, no. 17, pp. 9778-9783, 2001.

[87] A. Vejux and G. Lizard, "Cytotoxic effects of oxysterols associated with human diseases: induction of cell death (apoptosis and/or oncosis), oxidative and inflammatory activities, and phospholipidosis," Molecular Aspects of Medicine, vol. 30, no. 3, pp. 153-170, 2009.

[88] A. Rosello, G. Warnes, and U. C. Meier, "Cell death pathways and autophagy in the central nervous system and its involvement in neurodegeneration, immunity and central nervous system infection: to die or not to die-that is the question," Clinical and Experimental Immunology, vol. 168, no. 1, pp. 5257, 2012.

[89] G. G. Perrone, C. M. Grant, and I. W. Dawes, "Genetic and environmental factors influencing glutathione homeostasis in Saccharomyces cerevisiae," Molecular Biology of the Cell, vol. 16, no. 1, pp. 218-230, 2005.

[90] M. A. Joshi, N. H. Jeoung, M. Obayashi et al., "Impaired growth and neurological abnormalities in branched-chain $\alpha$-keto acid dehydrogenase kinase-deficient mice," Biochemical Journal, vol. 400, no. 1, pp. 153-162, 2006.

[91] Z. Li, S. M. Lukasik, Y. Liu et al., "A mutation in the Sswitch region of the Runt domain alters the dynamics of an allosteric network responsible for CBF beta regulation," Journal of Molecular Biology, vol. 364, no. 5, pp. 1073-1083, 2006.

[92] K.-I. Inoue, T. Shiga, and Y. Ito, "Runx transcription factors in neuronal development," Neural Development, vol. 3, article 20, 2008.

[93] Y. X. Chao, B. P. He, and S. S. W. Tay, "Mesenchymal stem cell transplantation attenuates blood brain barrier damage and neuroinflammation and protects dopaminergic neurons against MPTP toxicity in the substantia nigra in a model of Parkinson's disease," Journal of Neuroimmunology, vol. 216, no. 1-2, pp. 3950, 2009.

[94] Y. Eshed, K. Feinberg, S. Poliak et al., "Gliomedin mediates Schwann cell-axon interaction and the molecular assembly of the nodes of Ranvier," Neuron, vol. 47, no. 2, pp. 215-229, 2005.

[95] K. Feinberg, Y. Eshed-Eisenbach, S. Frechter et al., "A glial signal consisting of gliomedin and $\mathrm{NrCAM}$ clusters axonal $\mathrm{Na}^{+}$ channels during the formation of nodes of Ranvier," Neuron, vol. 65 , no. 4, pp. 490-502, 2010.

[96] R. Bonasio, E. Lecona, and D. Reinberg, "MBT domain proteins in development and disease," Seminars in Cell and Developmental Biology, vol. 21, no. 2, pp. 221-230, 2010.

[97] A. Dahiya, S. Wong, S. Gonzalo, M. Gavin, and D. C. Dean, "Linking the Rb and Polycomb pathways," Molecular Cell, vol. 8, no. 3, pp. 557-569, 2001.

[98] M.-Y. Wu, T.-F. Tsai, and A. L. Beaudet, "Deficiency of Rbbp1/Arid4a and Rbbp1l1/Arid4b alters epigenetic modifications and suppresses an imprinting defect in the PWS/AS domain," Genes and Development, vol. 20, no. 20, pp. 2859-2870, 2006.

[99] P. Korhonen, T. Tapiola, T. Suuronen, and A. Salminen, "Expression of transcriptional repressor protein $\mathrm{mSin} 3 \mathrm{~A}$ but not $\mathrm{mSin} 3 \mathrm{~B}$ is induced during neuronal apoptosis," Biochemical and Biophysical Research Communications, vol. 252, no. 1, pp. 274-277, 1998.

[100] J. Katahira, T. Miki, K. Takano et al., "Nuclear RNA export factor 7 is localized in processing bodies and neuronal RNA granules through interactions with shuttling hnRNPs," Nucleic Acids Research, vol. 36, no. 2, pp. 616-628, 2008.

[101] P. Jansen, K. Giehl, J. R. Nyengaard et al., "Roles for the proneurotrophin receptor sortilin in neuronal development, aging and brain injury," Nature Neuroscience, vol. 10, no. 11, pp. 14491457, 2007.

[102] S. Capsoni, G. Amato, D. Vignone, C. Criscuolo, A. Nykjaer, and A. Cattaneo, "Dissecting the role of sortilin receptor signaling in neurodegeneration induced by NGF deprivation," Biochemical and Biophysical Research Communications, vol. 431, no. 3, pp. 579-585, 2013.

[103] L. C. Xia, D. Ai, J. Cram, J. A. Fuhrman, and F. Sun, "Efficient statistical significance approximation for local similarity analysis of high-throughput time series data," Bioinformatics, vol. 29, no. 2, pp. 230-237, 2013.

[104] P. C. Holm, F. J. Rodríguez, J. Kele, G. Castelo-Branco, J. Kitajewski, and E. Arenas, "BMPs, FGF8 and Wnts regulate the differentiation of locus coeruleus noradrenergic neuronal precursors," Journal of Neurochemistry, vol. 99, no. 1, pp. 343352, 2006.

[105] R. Bajo-Grañeras, M. D. Ganfornina, E. Martín-Tejedor, and D. Sanchez, "Apolipoprotein D mediates autocrine protection of astrocytes and controls their reactivity level, contributing to the functional maintenance of paraquat-challenged dopaminergic systems," Glia, vol. 59, no. 10, pp. 1551-1566, 2011.

[106] R. Bajo-Grañeras, D. Sanchez, G. Gutierrez et al., "Apolipoprotein $\mathrm{D}$ alters the early transcriptional response to oxidative stress in the adult cerebellum," Journal of Neurochemistry, vol. 117, no. 6, pp. 949-960, 2011.

[107] D. Domenger, D. Dea, L. Theroux, L. Moquin, A. Gratton, and J. Poirier, “The MPTP neurotoxic lesion model of Parkinson's disease activates the apolipoprotein $\mathrm{E}$ cascade in the mouse brain," Experimental Neurology, vol. 233, no. 1, pp. 513-522, 2012.

[108] V. G. Khaindrava, E. A. Kozina, V. S. Kudrin et al., "Experimental modeling of preclinical and clinical stages of Parkinson's disease," Bulletin of Experimental Biology and Medicine, vol. 150, no. 5, pp. 566-569, 2011.

[109] R. Nandhagopal, L. Kuramoto, M. Schulzer et al., "Longitudinal evolution of compensatory changes in striatal dopamine processing in Parkinson's disease," Brain, vol. 134, no. 11, pp. 32903298, 2011. 
[110] B. Sampaio-Marques, C. Felgueiras, A. Silva et al., "SNCA $(\alpha$-synuclein)-induced toxicity in yeast cells is dependent on sirtuin 2 (Sir2)-mediated mitophagy," Autophagy, vol. 8, no. 10, pp. 1494-1509, 2012.

[111] A. Nykjaer and T. E. Willnow, "Sortilin: a receptor to regulate neuronal viability and function," Trends in Neurosciences, vol. 35, no. 4, pp. 261-270, 2012.

[112] R. D. Perea, R. C. Rada, J. Wilson et al., "A comparative white matter study with Parkinson's disease, Parkinson's disease with Dementia and Alzheimer's Disease," Journal of Alzheimer's \& Disease Parkinsonism, vol. 3, article 123, 2014.

[113] J. Eryilmaz, P. Pan, M. F. Amaya et al., "Structural studies of a four-MBT repeat protein MBTD1," PLoS ONE, vol. 4, no. 10, Article ID e7274, 2009.

[114] G. U. Höglinger, J. J. Breunig, C. Depboylu et al., "The pRb/E2F cell-cycle pathway mediates cell death in Parkinson's disease," Proceedings of the National Academy of Sciences of the United States of America, vol. 104, no. 9, pp. 3585-3590, 2007.

[115] M. Ramaswami, J. P. Taylor, and R. Parker, "Altered ribostasis: RNA-protein granules in degenerative disorders," Cell, vol. 154, no. 4, pp. 727-736, 2013.

[116] T. Vanderweyde, K. Youmans, L. Liu-Yesucevitz, and B. Wolozin, "Role of stress granules and RNA-binding proteins in neurodegeneration: a mini-review," Gerontology, vol. 59, no. 6, pp. 524-533, 2013.

[117] O. Binda, C. Nassif, and P. E. Branton, "SIRT1 negatively regulates HDAC1-dependent transcriptional repression by the RBP1 family of proteins," Oncogene, vol. 27, no. 24, pp. 33843392, 2008.

[118] L. Parkkinen, T. Pirttilâ, and I. Alafuzoff, "Applicability of current staging/categorization of $\alpha$-synuclein pathology and their clinical relevance," Acta Neuropathologica, vol. 115, no. 4, pp. 399-407, 2008.

[119] J. A. Obeso, M. C. Rodriguez-Oroz, C. G. Goetz et al., "Molecular cloning of porimin, a novel cell surface receptor mediating oncotic cell death," Nature Medicine, vol. 16, no. 6, pp. 653-661, 2010.

[120] A. H. Schapira and P. Jenner, "Etiology and pathogenesis of Parkinson's disease," Movement Disorders, vol. 26, no. 6, pp. 1049-1055, 2011.

[121] I. Ferrer, A. Martinez, R. Blanco, E. Dalfó, and M. Carmona, "Neuropathology of sporadic Parkinson disease before the appearance of parkinsonism: preclinical Parkinson disease," Journal of Neural Transmission, vol. 118, no. 5, pp. 821-839, 2011.

[122] G. Konopka, "Functional genomics of the brain: uncovering networks in the CNS using a systems approach," Wiley Interdisciplinary Reviews: Systems Biology and Medicine, vol. 3, no. 6, pp. 628-648, 2011. 


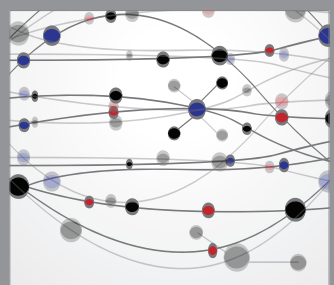

The Scientific World Journal
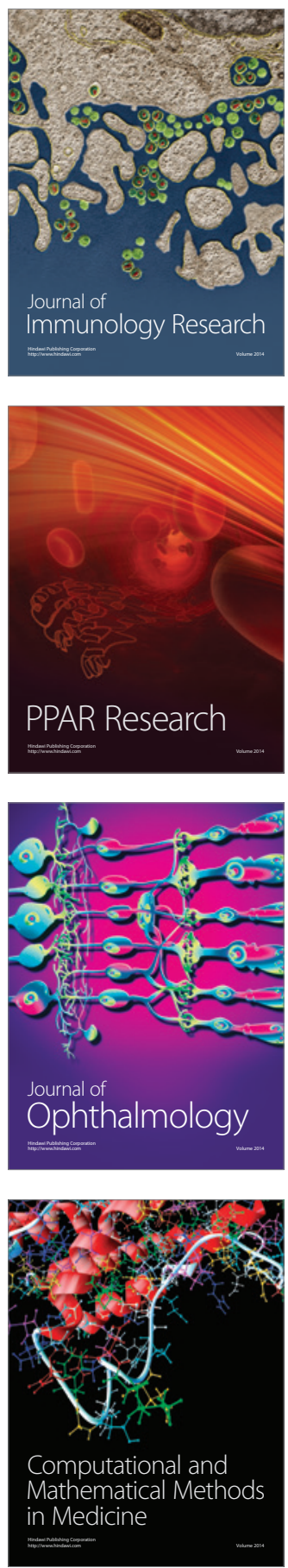

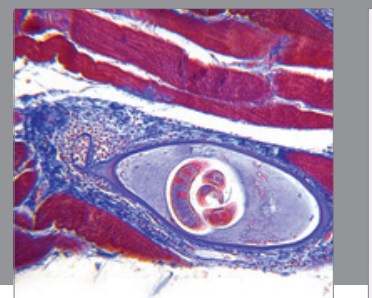

Gastroenterology

Research and Practice
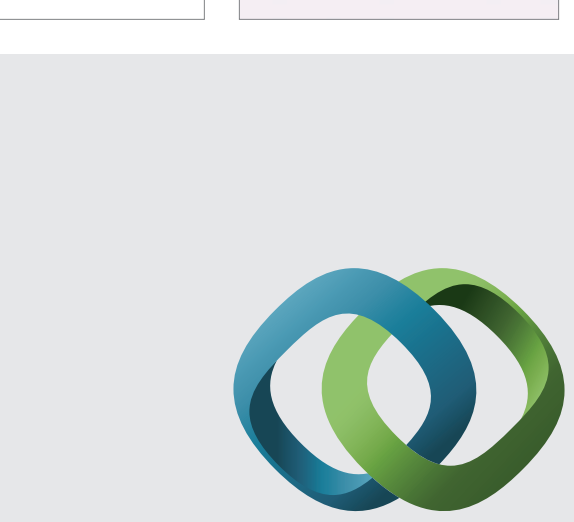

\section{Hindawi}

Submit your manuscripts at

http://www.hindawi.com
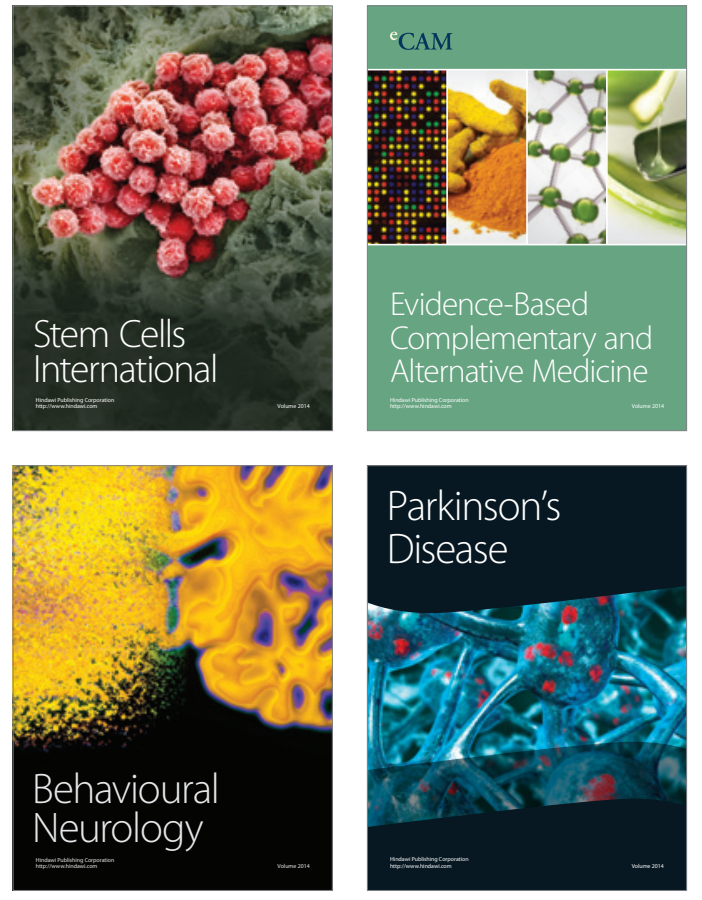
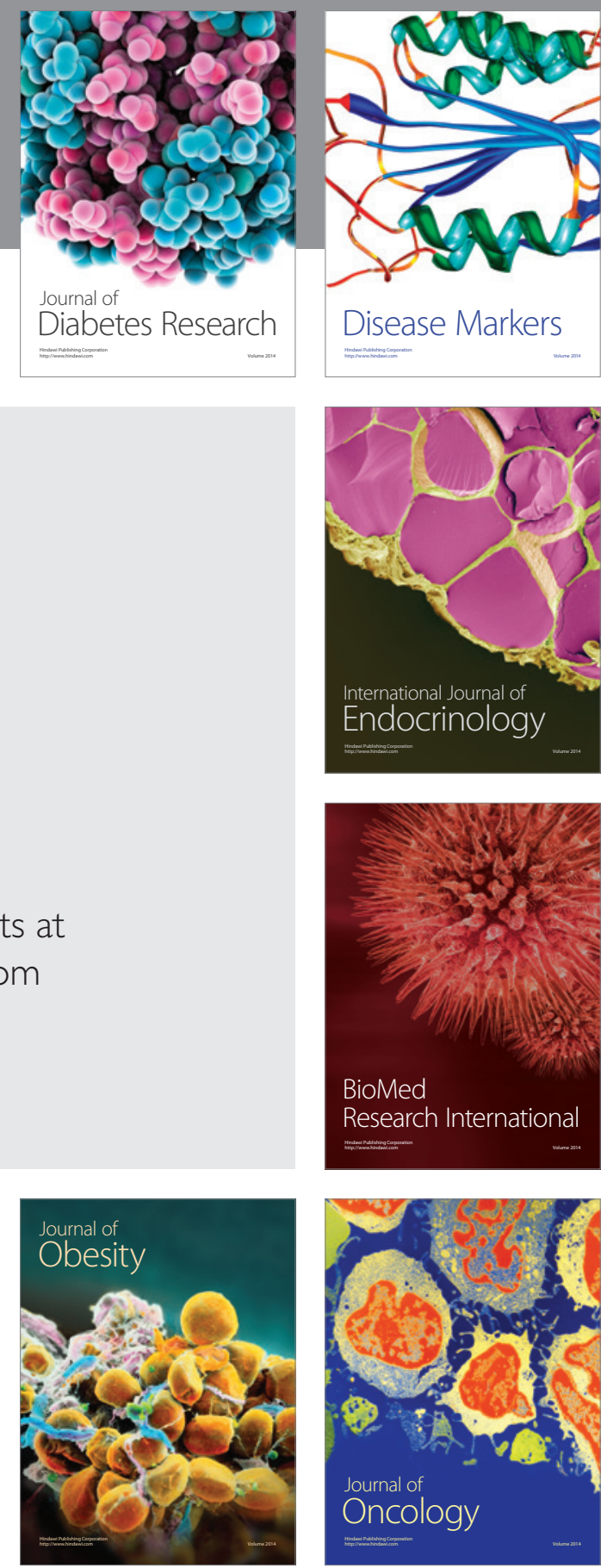

Disease Markers
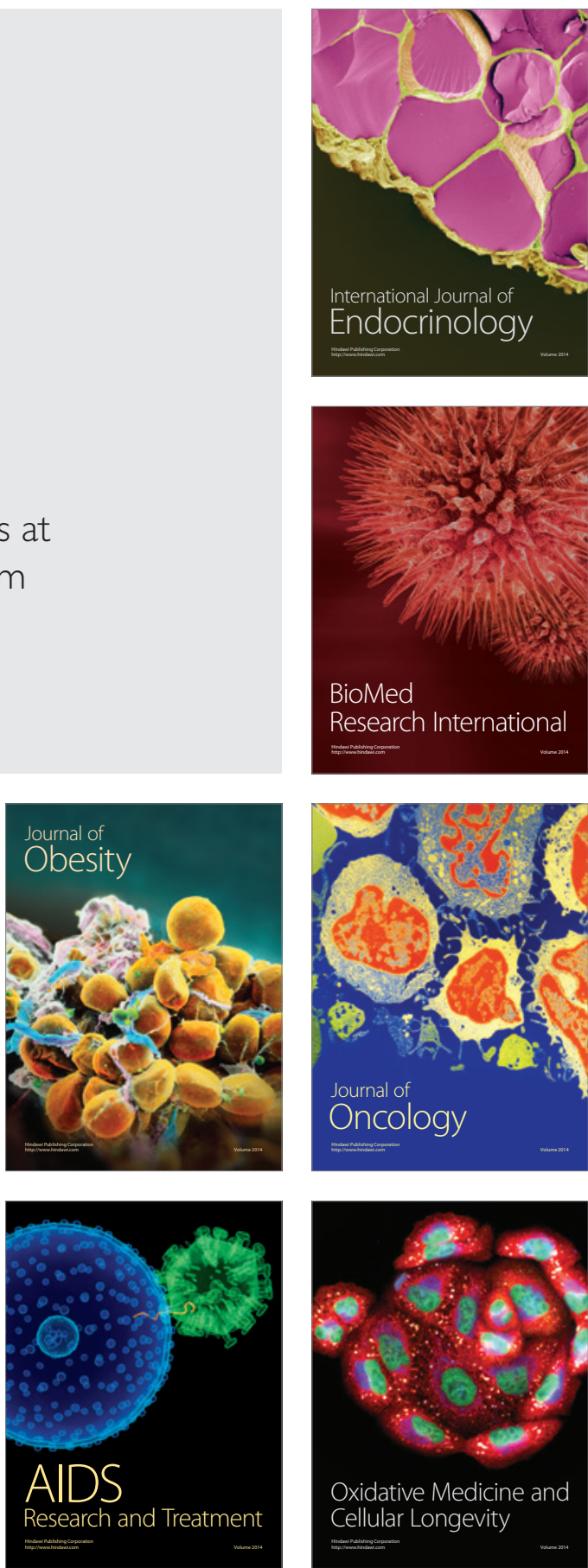